\title{
Constructing straight Poly-ionic liquid microchannels for fast anhydrous proton transport
}

\author{
Parashuram Kallem ${ }^{\dagger}$,Adela Eguizabal $\dagger^{\dagger}$ Reyes Mallada ${ }^{\not *}$ and Maria Pilar Pina ${ }^{\dagger *}$ \\ $\dagger$ Nanoscience Institute of Aragon. University of Zaragoza. Department of Chemical \& \\ Environmental Engineering, Edif. I+D+i, Campus Rio Ebro. C/Mariano Esquillor, s/n, 50018, \\ Zaragoza, Spain.
}

$\ddagger$ Networking Research Center on Bioengineering, Biomaterials and Nanomedicine, CIBERBBN, 50018 Zaragoza, Spain.

KEYWORDS: flexible electrolytes, poly imidazolium ionic liquids, polybenzimidazole microsieves, Cross linking, Microtransfer moulding, proton transport

\begin{abstract}
Poly-ionic liquids (PILs) have triggered great interest as all solid state flexible electrolytes because of safety and superior thermal, chemical and electrochemical stability. It is of great importance to fabricate highly conductive electrolyte membranes capable to operate above $120^{\circ} \mathrm{C}$ under anhydrous conditions and in absence of mineral acids, without sacrificing the mechanical behavior. Herein, the diminished dimensional and mechanical stability of poly[1(3H-imidazolium)ethylene]bis(trifluoromethanesulfonyl)imide has been improved thanks to its infiltration on a polybenzimidale (PBI) support with specific pore architecture. Our innovative solution is based on the synergic combination of an emerging class of materials and sustainable
\end{abstract}


large scale manufacturing techniques (UV polymerization and replication by microtransfermoulding). Following this approach, the PIL plays the proton conduction role and the PBI microsieve (SPBI) mainly provides the mechanical reinforcement. Among the resulting electrolyte membranes, conductivity values above $50 \mathrm{mS} \cdot \mathrm{cm}^{-1}$ at $200{ }^{\circ} \mathrm{C}$ and $10.7 \mathrm{MPa}$ as tensile stress are shown by straight microchannels of poly[1-(3Himidazolium)ethylene]bis(trifluoromethanesulfonyl)imide crosslinked with $\quad 1 \%$ of dyvinylbenzene embedded in a PBI microsieve with well-defined porosity (36\%) and pore diameter $(17 \mu \mathrm{m})$.

\section{INTRODUCTION}

The current movement towards sustainable and more efficient power production has shifted the bias from the conventional fuels and internal combustion engines and increased the interest on alternative fuels and power sources ${ }^{1}$. The Polymer Electrolyte Membrane Fuel Cell (PEMFC) is considered one of the most promising alternative power sources especially for sub-megawatt scale applications ${ }^{2}$. In particular, the fuel cell (FC) operation at high temperature is desirable since at temperatures over $120{ }^{\circ} \mathrm{C}$ overcome most of the functional problems currently associated with proton exchange membrane fuel cells (PEMFCs). Thus, catalyst CO poisoning, water management, efficiency (polarization effects and electrochemical reaction rates), and cogeneration possibilities are greatly improved. In this high temperature scenario, the most important challenges are mainly related to the electrolyte performance and durability. Polymer based electrolyte membranes have been actively investigated over the last years for the development of new generation of proton exchange membranes (PEMs) adequate for high

temperature applications ${ }^{3-6}$. Among those, poly-benzimidazole (PBI) has received a lot of 
attention because of its excellent chemical and thermal stability. Generally, PBI is used in thermal protective clothing and fire blocking applications. In particular, acid doped PBI membranes have been recognized as promising PEM materials operating at high temperatures ${ }^{7-9}$. More specifically, phosphoric acid doped PBI membranes ${ }^{10-14}$ exhibit excellent adequate proton conductivity, mechanical properties and fuel cross over behavior. However, pyrophosphoric acid formation ${ }^{12}$, catalyst deactivation due to the adsorption of phosphate anions ${ }^{15}$ and carbon support corrosion ${ }^{16}$ remain as the main shortcomings.

Advantages of ILs as electrolytes for Electrochemical Applications (paragraph 3)

Ionic liquids (ILs) are becoming progressively in valuable materials for electrochemical applications ${ }^{17-20}$ due to its unique properties such as negligible vapour pressure, thermal stability and non-flammability, combined with high ionic conductivity and wide electrochemical stability window. Accounting from the huge diversity of cation and anion combinations, they are recognized as multipurpose materials on the basis of their tunable physico-chemical properties (thermal and chemical stability, volatility, conductivity, polarity, melting point, viscosity, density etc.).

Opportunities of ILs for high temperature PEMFC and challenges behind (paragraph 4)

Particularly for PEM applications, thermal stability and non-volatile character of ILs outstands as the main advantages compared to mineral acid dopants. Some previous works deal with the incorporation of ILs and mineral acid (if applicable) at different molar composition on the PBI casting solution ${ }^{21-25}$. In this case, the key point is the miscibility between the IL and the polymer. Among those, the contribution from Liu et $\mathrm{al}^{24}$. about diethylmethylammonium trifluoromethanesulfonate - PBI blends outstands in terms of ionic eonductivity; conductivity, 
reaching values above $20 \mathrm{mS} \cdot \mathrm{cm}^{-1}$ at $160{ }^{\circ} \mathrm{C}$. So far, the attained results are considered inadequate in terms of electrochemical and/or durability performance for practical fuel cell operation. At temperatures above $100{ }^{\circ} \mathrm{C}$, migration of IL towards the cathode by electroosmotic drag was confirmed by Mamlouk et $\mathrm{al}^{25}$ on composite diethlyamine bisulphate/sulphate - PBI membranes under polarization conditions.

Immnobilization of ILs in porous supports by capillary forces (paragraph 5)

There is a challenging need for immobilizing RTILs in solid devices for material applications, while keeping their specific properties. Supported Ionic Liquid Membranes (SILM), widely used for gas separation ${ }^{26}$, has been scarcely attempted for FC applications ${ }^{27-29}$. This approach relies on RTILs immobilization in the pores of a porous support by capillary forces. Although the negligible protic ionic liquid vapor pressure alleviates one of the problems associated with traditional SILMs, namely liquid volatility; expulsion of the liquid from the membrane pores is a major concern. A proper design of the support, with sub-micron pores, combined with an ionic liquid having high surface tension could lead to SLIMs with adequate physical stability for applications involving moderate to high trans-membrane pressures ${ }^{30}$. Particularly on FC operation, the polymer membranes swelled with protic ionic liquids suffer from the hydrodynamical solvation phenomenon which limits the lifetime of the cell $1^{31}$.

On the use of Polymeric Ionic Liquids as electrolytes in PEMFCs (paragraph 6)

Polymerization of RTILs emerges as an attractive alternative in terms of safety, stability and mechanical properties. Polymeric ionic liquids (PILs) $)^{32-39}$ retain some of the unique properties of IL, such as thermal stability, tunable solution properties and chemical stability, which when combined with intrinsic polymer properties are anticipated to offer more advantages than ILs. 
Depending on the structure of the backbone of PILs, namely polycation or polyanion, the ionic conductivity will be associated with the transport of the counter-anions or counter-cations respectively. Free radical polymerization of RTILs monomers by photochemical initiation is very attractive due to the short reaction time and ambient working temperature. However, the "in situ" polymerization may introduce some impurities into the PILs such as unreacted monomer or initiator which may limit their electrochemical performance. Following this approach, all solid state proton conductive films have been recently prepared in our group ${ }^{37}$ by UV photo-assisted ( $\lambda=365 \mathrm{~nm}$ for $15 \mathrm{~min}$ ) polymerization of commercial available ammonium and imidazolium RTILs with vinyl-based reactive groups. Among the tested, the poly[1-(3Himidazolium)ethylene] bis(trifluoromethanesulfonyl)imide with 2.5 mol.\% mol\% of divinylbenzene as cross-linker outstands as the most promising. Similarly, Ortiz et $\mathrm{al}^{40-41}$ have recently reported the fuel cell performance of PILs based on 1-(4-sulfobutyl)-3-vinylimidazolium trifluoromethanesulfonate] with divinylbenzene $(10 \mathrm{~mol} \%)$ as cross linker. Such electrolyte membrane showed a maximum power density of $33 \mathrm{~mW} \cdot \mathrm{cm}^{-2}$ at $25{ }^{\circ} \mathrm{C}$ under non-humidified conditions; but performance declined at temperatures above $50{ }^{\circ} \mathrm{C}$ due to membrane softening.

Composite electrolyte membranes based on the polymeric ionic liquid matrix from 1-(4sulphobutyl)-3-vinylimidazolium trifluoromethanesulphonate and its analogue nonpolymerizable ionic liquid 1-(4-sulphobutyl)-3-methylimidazolium trifluoromethanesulphonate, have been developed for PEMFC applications ${ }^{43}$. Stable electrolyte membranes containing 10 $\mathrm{wt} \%$ of the ionic liquid showed the highest conductivity of $293 \mathrm{mS} \cdot \mathrm{cm}^{-1}$, and the best FC performance, with a peak power density of $49 \mathrm{~mW} \cdot \mathrm{cm}^{-2}$ at $40{ }^{\circ} \mathrm{C}$ without external humidification. However, their mechanical and dimensional stability is not adequate for high temperature PEMFC application. 
On the combination of PIL and PBI for high temperature PEMFCs (paragraph 7)

PIL-PBI blend membranes with adequate thermal and mechanical stability have been successfully prepared from poly(diallyl dimethyl ammonium trifluoride methane sulphonate) ${ }^{44}$. Upon phosphoric acid doping, the reported proton conductivity and power density values were $70 \mathrm{mS} \cdot \mathrm{cm}^{-1}$ at $150{ }^{\circ} \mathrm{C}$ and $515 \mathrm{~mW} \cdot \mathrm{cm}^{-2}$ at $160{ }^{\circ} \mathrm{C}$, respectively. It is noteworthy to underline that the electrochemical performance of such blended PIL-PBI membranes is strongly dependent on the phosphoric acid uptake values (circa $10 \mathrm{~mol} / \mathrm{RU}$ ).

Purpose of this work: In situ polymerization of ILs on PBI microsieves (paragraph 8-10)

Unlike previously, our approach relies on the use of porous PBI matrix as poly-ionic liquid container. The underlying rationale is based on the pore-filling electrolyte membrane concept proposed by Yamaguchi for fuel cross-over suppression on direct methanol fuel cells ${ }^{45}$. The consecution of a polymeric container with optimized pore architecture is extremely essential ${ }^{46}$ since the performance of PEM based on immersing a porous support into ILs, mainly depends on the porous structure. Thus, the present work aims to improve both, the ion conductivity and the dimensional stability of the PIL supported membranes by a proper design of the porous architecture.

The preparation of porous PBI membranes by phase inversion method, by leaching out a

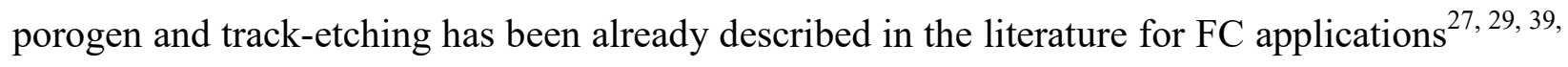
47-49. Highly porous asymmetric PBI prepared by soft-template method, using 1-ethyl-3methylimidazolium bis(trifluoromethanesulfonyl)imide as porogen, has been recently reported by Hsu et al. $^{48}$ In general, high porosity usually leads to the decrease of tensile strength ${ }^{46,48}$. Nevertheless, the mechanical properties are often sacrificed to obtain sufficient conductivity. 
This fact is unambiguously hampering the large scale commercialization of reliable PEMs for high temperature applications. Our group ${ }^{39}$ has investigated the "in situ" UV polymerization 1H-3-vinylimidazolium bis(trifluoromethanesulfonyl)imide on a highly porous sponge-like PBI matrix (above 75 vol\%). While most of our attention was focused on the conduction performance, above $300 \mathrm{mS} \cdot \mathrm{cm}^{-1}$ at $200{ }^{\circ} \mathrm{C}$ under anhydrous conditions; the fragility of the membranes, i.e. 0.2 $\mathrm{GPa}$ as Young Modulus and 1.3 $\mathrm{MPa}$ as tensile strength, hindered the proper handling.

In this work, the electrolyte membranes are composed of two materials: an inert PBI microsieve (SPBI) having straight pores on the micrometer scale $(20 \mu \mathrm{m}$, aspect ratio 1) and $36 \%$ in porosity; and 1-H-3-vinylimidazolium bis(trifluoromethanesulfonyl)imide ionic liquid that fills the pores and polymerizes inside the pores of the PBI substrate. The filling poly-ionic liquid exhibits proton conductivity and the PBI skeleton provides the mechanical reinforcement. Compared to sponge-like supports, the PBI microsieve will facilitate the electrolyte filling. Furthermore, enhanced conduction performance would be expected as the effective pathways become shorter ${ }^{28}$. Thus, a comprehensive physico-chemical characterization of such novel ion conducting membranes, including the modification by crosslinking, is accomplished and compared with published results for similar single components.

\section{EXPERIMENTAL}

\subsection{Materials}

All chemical reagents and solvents listed in the following were used as received: Poly[2,2-(mphenylene)-5,5bibenzimidazole] (PBI Fumion APH Ionomer, Mw 59,000-62,000, Fumatech), LiCl(99 wt\%, Sigma-Aldrich),1-H-3-vinylimidazoliumbis(trifluoromethane sulfonyl)imide (98 
wt $\%, \quad$ SOLVIONIC), Divinylbenzene $\quad(80 \quad$ wt $\%, \quad$ Sigma-Aldrich $), \quad$ 2-hidroxy-2methylpropiophenone (97 wt\%, Sigma-Aldrich), N,N-dimethylacetamide (99.8 wt\%, Aldrich).

\subsection{PBI solution preparation}

$2 \mathrm{~g}$ of PBI Fumion powder, $0.01 \mathrm{~g}$ of $\mathrm{LiCl}$ (as a stabilizer), and $40 \mathrm{~mL}$ (9.3 $37.6 \mathrm{~g}$ ) of N,Ndimethylacetamide were mixed in the autoclave then dissolved under autogenous pressure at 240 ${ }^{\circ} \mathrm{C}$ for $48 \mathrm{~h}$ to obtain the starting PBI solution of $5 \mathrm{wt} . \%$ in DMAc.

\subsection{Fabrication of PBI microsieves by microtransfer moulding technique}

PBI microsieves (SPBI) are prepared by microtransfer moulding technique from a reinforcement pattern of the poly (dimethylsiloxane) (PDMS) mould following our previous work ${ }^{51}$. The main processes (see Figure 1) to obtain the straight porous PBI membrane are: i) SU-8 master fabrication (steps S1 to S4); ii) PDMS soft-mould fabrication (steps S5 to S6); and iii) PBI membrane formation (steps S7 to S8).

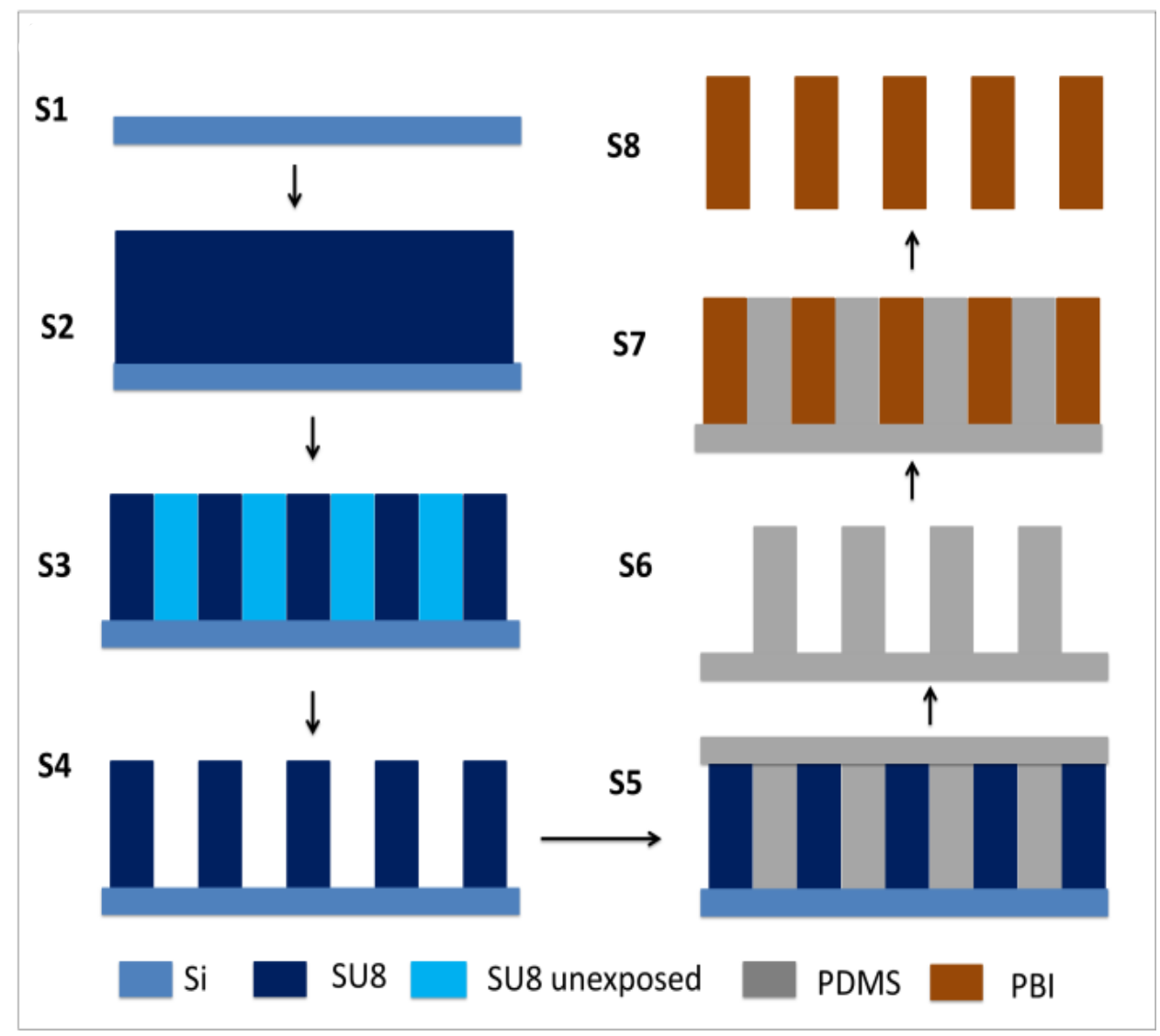


Figure 1. Schematic overview of micro transfer moulding process for the preparation of PBI microsieves: steps $\mathrm{S} 1$ to $\mathrm{S} 8$.

The SU-8 masters were prepared by photolithography and the PDMS moulds by pre-polymer casting (see supporting information for the procedure, Table S1). Following this procedure, two different PDMS moulds containing uniform cylindrically shaped pillars with pitch value (center to center distance) of $30 \mu \mathrm{m}$ were prepared: P15 mould with pillars $15 \mu \mathrm{m}$ high and $20 \mu \mathrm{m}$ in diameter; and, P20 mould with pillars $20 \mu \mathrm{m}$ high and $18 \mu \mathrm{m}$ in diameter, respectively.

The SPBIs were prepared by transferring the pattern on the PDMS back into a replica of the original SU-8 master by the solution casting method. The starting PBI solution (5wt. \%) was further diluted with DMAc to ensure the complete filling of the PDMS mould. The final PBI solution, once sonicated, was cast onto PDMS mould lying in the oven tray at $60{ }^{\circ} \mathrm{C}$ and perfectly aligned with the horizontal axis to ensure a homogeneous coverage (Figure 1.step S7). After casting, DMAc was evaporated by natural convection from 60 to $90{ }^{\circ} \mathrm{C}$ at $10{ }^{\circ} \mathrm{C} / \mathrm{h}$. Finally, the system was kept at $90{ }^{\circ} \mathrm{C}$ for $12 \mathrm{~h}$ to ensure the solvent evaporation by forced convection and the fabricated SPBI was spontaneously released from the elastomeric PDMS support (Figure 1.step S8).

The resulting microperforated PBI foil was immersed in boiling deionized water for $5 \mathrm{~h}$ to remove $\mathrm{LiCl}$ and finally dried at $110{ }^{\circ} \mathrm{C} / 50$ mbar to remove all the traces of the solvent. The thickness of the as prepared samples was measured with Baxlo 4000/FILM precision micrometer with an accuracy of 1 micron.

\subsection{5 Preparation of reinforced PIL electrolytes on PBI microsieves}


The SPBI is firstly infiltrated with the monomeric ionic liquid (MIL) 1-H-3-vinylimidazolium bis(trifluoromethane sulfonyl)imide following the general procedure already described in our previous works ${ }^{28-29,} 39$ (see supporting information for the procedure, Fig S1 and Fig S2). Basically, the MIL: Acetone $(1: 10 \mathrm{v} / \mathrm{v})$ solution containing the photoinitiator $(2 \mathrm{wt} . \%$. referred to the MIL), and the crosslinker agent (from $0.2 \mathrm{~mol} \%$ up to $1 \mathrm{~mol} \%$ referred to the MIL) was dropped on the membrane top surface at room temperature while dry $\mathrm{N}_{2}$ was sweeping the bottom surface. Subsequently, the MIL and cross-linking agent (if applicable) reacts inside the pores of the PBI microsieve (see Figure 2) by exposure to UV light (365 nm, Vilmer Lourmat lamp) with an intensity of $2.4 \mathrm{~mW} / \mathrm{cm}^{2}$ at the sample surface for $2 \mathrm{~h}$ on each side. After polymerization, the electrolyte membrane is gently wiped from any residuals with lab paper and removed from the device with the help of razor blade.

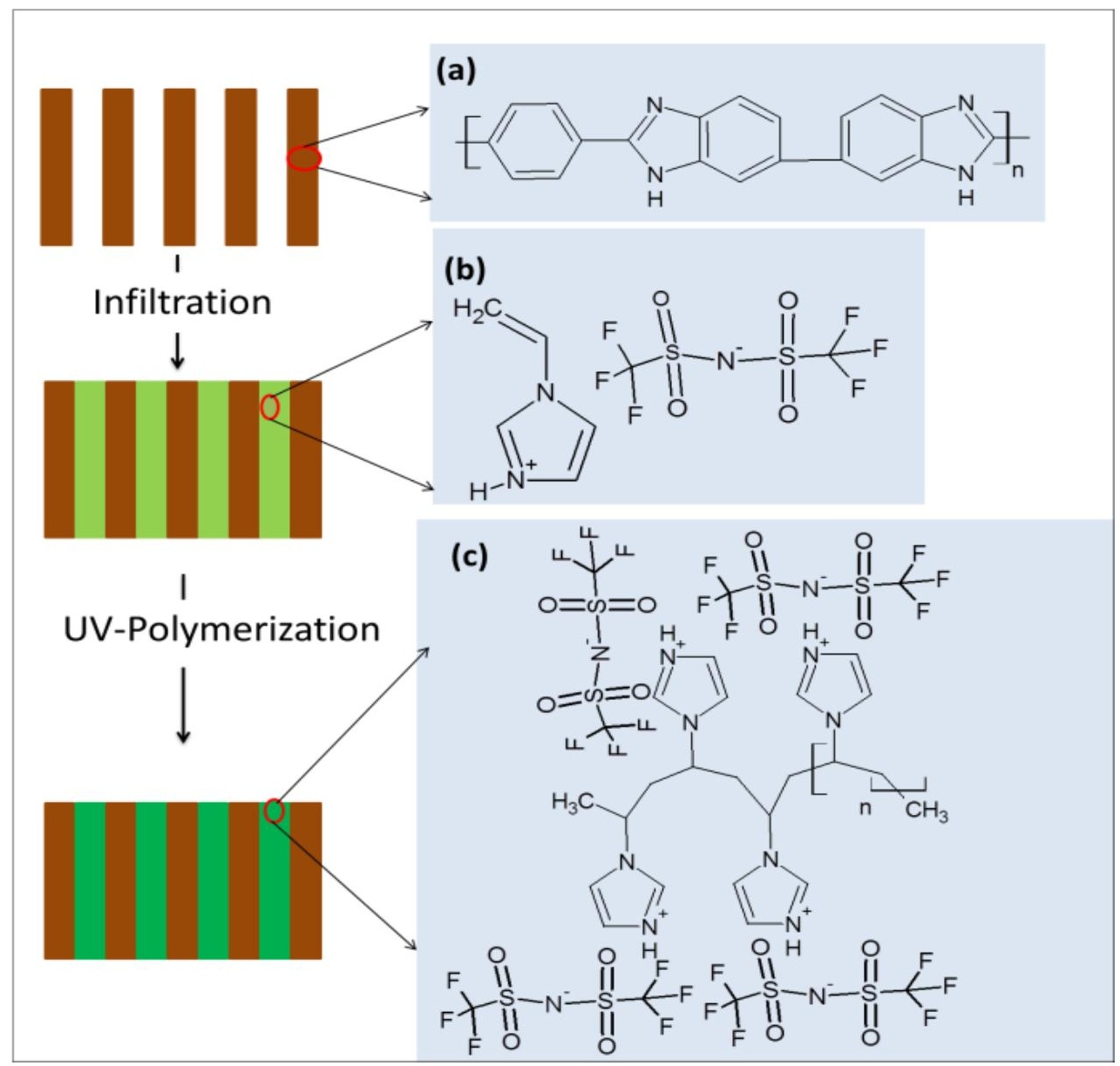


Figure 1.B)2. Schematic illustration of the pore filling membrane and chemical structures of: (a) repeating unit of Poly[2,2-(m-phenylene)-5,5-bibenzimidazole; (b) monomeric ionic liquid 1-H-

3-vinylimidazolium bis(trifluoromethanesulfonyl)imide; $\quad$ (c) homopoly[1-(3Himidazolium)ethylene]bis(trifluoromethanesulfonyl)imide.

The amount of the electrolyte in the final PIL-SPBI membranes was experimentally determined by weight differences before and after introducing PIL and also by TGA analysis. These values were compared with those theoretically calculated from the pore volume of the PBI container and the estimated PIL density values: $2.2,2.3,2.56$ and $2.7 \mathrm{~g} / \mathrm{cm}^{3}$ for PIL- $0 \% \mathrm{CL}$, PIL- $0.2 \% \mathrm{CL}$, PIL-0.5\%CL and PIL-1\%CL respectively.

\subsection{Characterization methods}

\subsubsection{Porosity-Morphological characterization}

Morphology, thickness and pore size of the as prepared SPBI membranes and homogeneity of the SPBI-PIL membranes have been studied by scanning electron microscopy SEM (FEG INSPECT 50).

The porosity of the as prepared PBI microsieves was determined by a Helium displacement pycnometer (MicroMetrics AccuPyc 1330) equipped with $1 \mathrm{~cm}^{3}$ sample module. The reproducibility is typically within $\pm 0.01 \%$ of the nominal sample capacity. The herein reported porosity values were evaluated on specimens above $30 \mathrm{~cm}^{2}$ in surface area (i.e. above $100 \mathrm{mg}$ ).

\subsubsection{SEM-characterization}

\subsubsection{ATR-FTIR Spectra Measurements}


ATR-FTIR analyses (Bruker VERTEX 70 equipped with Golden Gate ATR from 4000 to 600 $\mathrm{cm}^{-1}, 256$ scans and resolution of $4 \mathrm{~cm}^{-1}$ ) were performed at room temperature to assess about the photopolymerization evolution and to investigate any possible interactions between the benzimidazole from the SPBI and the poly[1-(3Himidazolium)ethylene]bis(trifluoromethanesulfonyl)imide.

\subsubsection{Thermal studies}

Thermogravimetric analysis (TGA) was carried out using a Q500 IR TA instrument to evaluate the composition and thermal behavior of the as prepared PIL-SPBI membranes with and without cross linker. Studies were conducted using 4-5 mg samples, in the temperature range from room temperature to $900{ }^{\circ} \mathrm{C}$ at a controlled heating rate of $z^{\circ} \mathrm{C} 2{ }^{\circ} \mathrm{C} / \mathrm{min}$ under an inert atmosphere $\left(\mathrm{N}_{2}\right)$.

\subsection{4 Mechanical properties}

The mechanical properties of the as prepared membranes were analyzed by extensional rheology to specify the mechanical behavior, i.e. Young modulus and tensile stress, as a function of the cross-linker content. This analysis was carried out using a rheometer MCR 301 (Anton Paar) equipped with the Universal Extensional Fixture UXF12. The temperature was controlled at 25 ${ }^{\circ} \mathrm{C}$ with a CTD180 Peltier system. The samples tested were $-4 \times 1 \mathrm{~cm}^{2} 4 \times 1 \mathrm{~cm}^{2}$ rectangles cut in different parts of the membranes. For a given membrane composition, the mechanical properties result from the average of at least 3 different samples.

\subsection{5 Proton conductivity}

Electrochemical properties of all the samples with and without cross linker were studied by Impedance Spectroscopy (EIS) using an Agilent 4294A Precision Impedance Analyzer from 40 $\mathrm{Hz}$ to $110 \mathrm{MHz}$. Basically, through-plane conductivity measurements at anhydrous conditions, 
i.e. by sweeping with $100 \mathrm{~cm}^{3} \mathrm{~N}_{2} \mathrm{STP} / \mathrm{min}$ (from certified high purity gas cylinder $>99.998 \%$ ), have been performed up to $200{ }^{\circ} \mathrm{C}$ in a closed home-made stainless-steel conductivity cell PTFE lined inside provided with annular gold electrodes $(11 \mathrm{~mm}$ outlet diameter and $6.5 \mathrm{~mm}$ inlet diameter). The electrolyte resistance $\left(\mathrm{R}_{2}\right)$ was determined from the real impedance-axis intercept of the Nyquist plot (see Fig S3 and Table S2 of the supporting information). Thus, the proton conductivity was accordingly calculated following the procedure already described in our previous works $29,37,39,47$. From conductivity performance, the apparent activation energy was evaluated assuming an Arrhenius type dependence ${ }^{25,39}$.

\section{RESULTS AND DISCUSSIONS}

\subsection{Fabrication of PBI microsieves by micro transfer moulding technique}

The successful preparation of PBI micresieves SPBIs mainly relies on the wetting properties of the PDMS mould with the casting solution. Thus, the effect of PBI eencentration amount in the final DMAc solution on the wetting of P20 and P15 moulds was firstly investigated (see supporting information for the procedure).

Table 1. Preparation of SPBIs by casting of P20 mould.

\begin{tabular}{cccccc}
\hline $\begin{array}{c}\text { SPBI } \\
\text { sample }\end{array}$ & $\begin{array}{c}\text { Amount of PBI } \\
\text { solution at } 5 \\
\mathrm{wt} \%(\mathrm{~g})^{*}\end{array}$ & $\begin{array}{c}\text { Final PBI } \\
\text { Concentration } \\
(\mathrm{wt} \%)\end{array}$ & $\begin{array}{c}\text { PBI in } \\
\text { casting } \\
\text { solution } \\
(\mathrm{mg})^{*}\end{array}$ & $\begin{array}{c}\text { Open } \\
\text { pores }\end{array}$ & $\begin{array}{c}\text { Average } \\
\text { thickness } \\
(\mu \mathrm{m})^{* *}\end{array}$ \\
\hline $\mathrm{P} 20-2$ & 2 & 1.13 & 100 & No & $21.8 \pm 0.6$ \\
$\mathrm{P} 20-1.8$ & 1.8 & 1.06 & 90 & No & $19.9 \pm 0.3$ \\
$\mathrm{P} 20-1.5$ & 1.5 & 0.88 & 75 & Yes & $16.5 \pm 0.9$ \\
\hline
\end{tabular}


* For the casting of P20 mould at wafer level, i.e. filling of $0.11 \mathrm{~cm}^{3} ; * *$ evaluated by SEM

Table 1 compiles the main characteristics of the PBI microsieves obtained by casting of P20 mould. Among the prepared SPBIs, the best well-defined and thicker SPBI membranes were obtained using P20-1.5 casting solution conditions. A digital picture of the so obtained SPBI foil is shown in Figure 23 , where cross section and top surface SEM analyses after release from the P20 mould are also included. As it can be observed, homogeneous and continuous PBI microsieves have been fabricated without any deformation in the replicated features (see Figure 23.A). The average pore diameter values, estimated by SEM analyses, are $18.4 \mu \mathrm{m}$ and $16.8 \mu \mathrm{m}$ for the mould side and the airside respectively. In addition, the porosity estimated by SEM agrees with the He picnometry measurement, i.e. $36 \pm 0.46 \%$.

Unlike the above, Figure 23 .B displays the morphology of P20-1.8 type samples where a thin dense layer on top responsible for the pore clogging is clearly distinguished. This effect is attributed to a minor excess in the amount of PBI solution used for the mould casting. On the contrary, the incomplete pore filling of the P20 mould is clearly illustrated on P20-2 sample (see in Fig S4 of the supplementary information). The attained asymmetric structure, with a dense PBI layer $10 \mu \mathrm{m}$ thick, arises from wettability issues due to the concentration of the casting solution $(1.0813 \mathrm{wt} \%)$.

Following a similar approach, thinner PBI microsieves were also fabricated by replication from P15 mould. Table S3 of the supplementary information summarizes the specific conditions for the consecution of well-defined SPBI membranes with open pores and $8 \mu \mathrm{m}$ thick (see Fig S5). 
These samples have not been further considered for the purposes of this work due to handling constraints.

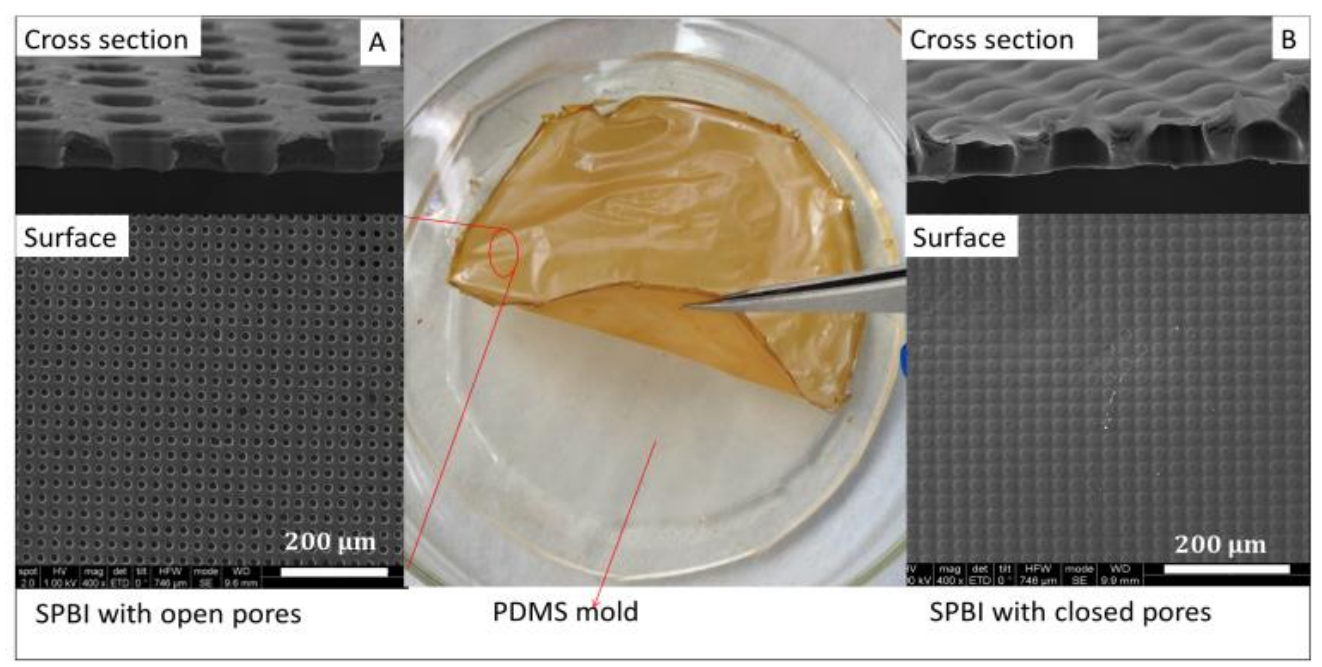

Figure 3. Fabrication of SPBIs by microtransfer moulding. SEM images of SPBI membranes with: A) open pores (P20-1.5 type samples); and, B) closed pores (P20-1.8 type samples).

\subsection{Pore filling of PBI microsieves and in-situ Polymerization}

The protic 1-H-3-vinylimidazolium bis(trifluoromethanesulfonyl)imide monomeric ionic liquid (MIL) has been chosen for the preparation of PIL-SPBI electrolyte membranes accounting from its proton conductivity and based on its high conductivity, low water uptake values as well as thermal stability ${ }^{37}$ (see Fig S6 of the supplementary information). Generally, ILs has a higher viscosity than regular solvents. Viscosity was firstly investigated prior to the infiltration of the monomeric Ionic liquid into SPBI homogeneously (see Fig S1A of the supplementary information. Additionally, the contact angle (CA) of 1-H-3vinylimidazoliumbis(trifluoromethane sulfonyl)imide liquid on dense PBI and SPBI membranes was measured. Obtained $\mathrm{CA}\left(^{\circ}\right)$ values for MIL were $26.04 \pm 0.13$ and $23.02 \pm 0.11$ for dense PBI and SPBI membranes, respectively (see Table S4); thus, relatively small compared to those 
measured for water, $83.2 \pm 0.32$ and $73.1 \pm 0.21$ for dense PBI and SPBI membranes, as already reported $^{30}$. These properties make MIL an appropriate wetting liquid for the pore filling of SPBIs.

The prepared composite PIL-SPBI electrolyte membranes with and without cross-linker are listed in Table 2. The nomenclature adopted for the membrane description includes the PDMS mold, the PBI content in the casting solution and the CL percentage in the MIL solution. Thus, membrane P20-1.5-0\%CL was prepared by in-situ polymerization of MIL into P20-1.5 type microsieve without any cross linker; whereas P20-1.5-0.2\%CL, P20-1.5-0.5\%CL, and P20-1.5$1 \% \mathrm{CL}$ membranes were based on MIL with $0.2,0.5$ and $1 \mathrm{~mol} \% \mathrm{CL}$ content referred to the MIL respectively. In order to assess about the conduction performance of PIL-SPBI samples, pure PIL membranes $^{39}$ (see Fig S7 of the supplementary information) without and with 1 mol\% CL, denoted as PIL and PIL-1\% respectively; and, phosphoric acid (PA) doped SPBI, denoted as P20-1.5-PA, prepared by SPBI immersion in $11 \mathrm{M}$ acid solution for $24 \mathrm{~h}$ at $80{ }^{\circ} \mathrm{C}^{47}$ were also fully studied.

Table 2. Main characteristics of the PIL-SPBI electrolyte membranes prepared for this work.

\begin{tabular}{|c|c|c|c|c|c|c|c|}
\hline \multirow[t]{2}{*}{ PEM code } & \multirow[t]{2}{*}{$Z^{*}$} & \multicolumn{3}{|c|}{ PIL content (wt. \%) } & \multicolumn{3}{|c|}{$\sigma\left(\mathrm{mS} \cdot \mathrm{cm}^{-1}\right)$ at $150^{\circ} \mathrm{C}$} \\
\hline & & Theo $^{1}$ & $\operatorname{Exp}^{2}$ & TGA & $5 \mathrm{~h}$ & $24 \mathrm{~h}$ & $50 \mathrm{~h}$ \\
\hline PIL & $95 \pm 1 \mu \mathrm{m}$ & - & - & - & 330.8 & - & - \\
\hline PIL-1\%CL & $85 \pm 1 \mu \mathrm{m}$ & - & - & - & 309.2 & - & - \\
\hline P20-1.5-PA & $22 \pm 1 \mu \mathrm{m}$ & - & $302^{3}$ & - & 9.5 & 8.4 & 7.0 \\
\hline
\end{tabular}




\begin{tabular}{cccccccc}
\hline P20-1.5-0\%CL & $23 \pm 1 \mu \mathrm{m}$ & 51.9 & 46.1 & 45.8 & 48.1 & 46.5 & 43.5 \\
$\mathrm{P} 20-1.5-0.2 \% \mathrm{CL}$ & $23 \pm 1 \mu \mathrm{m}$ & 52.9 & 48.6 & 46.6 & 42.2 & 38.8 & 38.4 \\
$\mathrm{P} 20-1.5-0.5 \% \mathrm{CL}$ & $23 \pm 1 \mu \mathrm{m}$ & 54.3 & 53.7 & 53.5 & 38.5 & 36.6 & 36.3 \\
& & & & & & & \\
$\mathrm{P} 20-1.5-1 \% \mathrm{CL}$ & $24 \pm 1 \mu \mathrm{m}$ & 55.4 & 58.5 & 59.3 & 35.5 & 35.1 & 35.0
\end{tabular}

*Average thickness from 3 different samples; ${ }^{1}$ Theorietical based on the density of PIL and the nominal porosity; ${ }^{2}$ based on gravimetry; ${ }^{3} \mathrm{PA}$ content in $\mathrm{wt} \%$ of $\mathrm{PA}$ : equivalent to 9.5 doping level in molar ratio.

As shown in Table 2, the experimental PIL loadings increase with the CL content: from $46.1 \%$ on $\mathrm{P} 20-1.5-0 \% \mathrm{CL}$ sample up to $58.5 \%$ for $\mathrm{P} 20-1.5-1 \% \mathrm{CL}$. This observation is mainly attributed to the PIL density variation as a function of CL content: values varying from 2.2 to $2.7 \mathrm{~g} / \mathrm{cm}^{3}$ for PIL-0\%CL and PIL-1\%CL, respectively. In general, the theoretical electrolyte loadings reasonably match with those calculated from gravimetry and TGA measurements. The PIL/PBI wt. ratio derived from TGA experiment, i.e. 0.84 for $36 \%$ porosity, correlates well with the previously reported value ${ }^{39}$ for PIL supported on randomly porous PBI supports, i.e. 1.95 for $80 \%$ porosity. This observation also supports the complete pore filling of the PBI microsieve as illustrated on Figure $34 \mathrm{~g}$.

SEM analysis of the SPBIs before and after electrolyte pore filling is shown in Figure 34 . The uniform and complete filling of SPBI pores with PIL is the key factor of PEM performances. Thus, surface and cross-sectional images of PIL-SPBI membranes with and without cross linker are displayed in Figure $34 \mathrm{c}$ to Figure $34 \mathrm{f}$. In general, the boundary layer between the PIL and the wall surface of the microporous PBI container is almost indistinguishable, in agreement with the chemical compatibility among both components. However, an excess of the electrolyte is 
observed on the top surface P20-1.5-1\%CL sample (see Figure 34e). This behavior correlates with the electrolyte loadings compiled in Table 2 , and it is related to the density-solubility of the PIL-1\%CL electrolyte in acetone that hinders the wiping performed after UV curing. Finally, the complete and uniform filling of SPBI pores with PIL in absence of cracks and defects is clearly shown in Figure 34g, with the SEM image of the curly PIL-SPBI foil at lower magnification (x400).

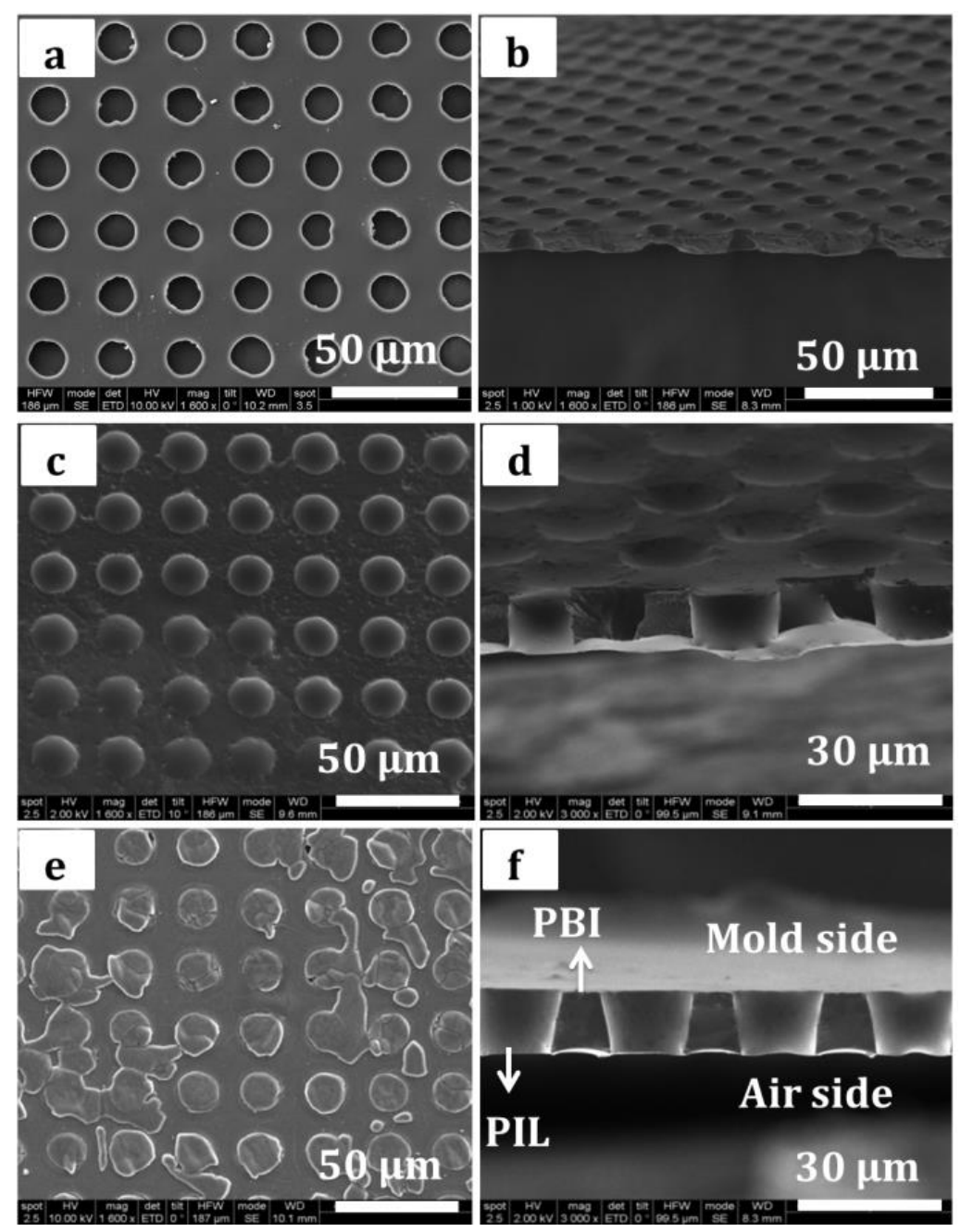




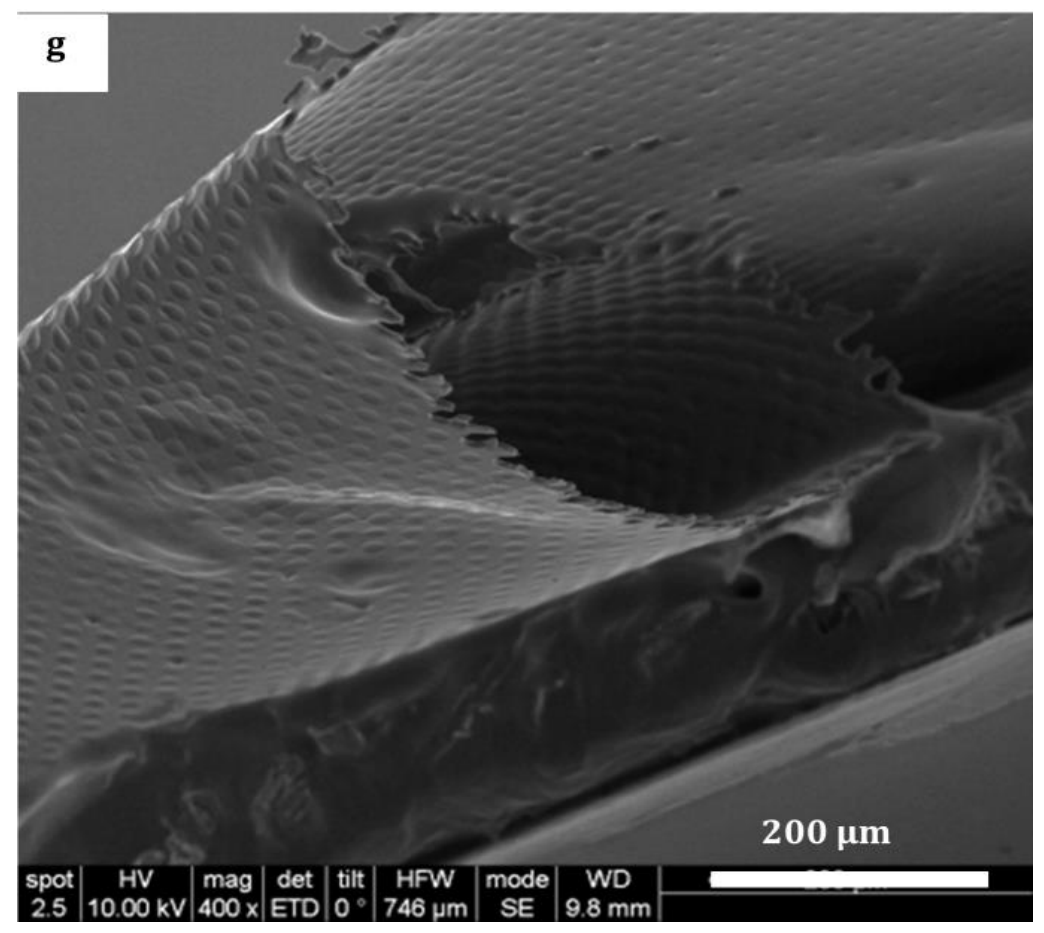

Figure 3 4. SEM images of SPBI support and PIL-SPBI membranes after pore filling: a) P20-1.5 surface; b) P20-1.5 cross section; c) P20-1.5-0\%CL surface; d) P20-1.5-0\%CL cross section; e) P20-1.5-1\%CL surface; f) P20-1.5-1\%CL cross section; g) P20-1.5-0\%CL at low magnification (400 X x).

The success in the photo-polymerization of vinyl-polymerizable groups from the ionic liquid has been corroborated by FTIR analysis. Thus, ATR-FTIR spectra of the composite membranes before, denoted as MIL-SPBI, and after UV radiation exposure for $2 \mathrm{~h}$ (PIL-SPBI) are provided in Figure 4 5.A. The intense absorption bands in the $1400-1000 \mathrm{~cm}^{-1}$ spectral region, observed in both MIL-SPBI and PIL-SPBI samples, are characteristics of the SO2 and SNS vibrational modes of the bis(trifluoromethanesulfonyl)imide [TFSI] anion ${ }^{52}$. The characteristic infrared absorbance bands adopted to monitor the disappearance of the vinyl-monomer were 1665-1630 $\mathrm{cm}^{-1}$ (stretching vibration in $-\mathrm{CH}=\mathrm{CH} 2$ ) and $995-920 \mathrm{~cm}^{-1}$ (out of plane bending of $-\mathrm{CH}=\mathrm{CH} 2$ 
groups). Separate spectral analysis on pure PIL samples, as shown in Fig. S8 of the supplementary information, as a function of UV exposure time (from 40 min up to $2 \mathrm{~h}$ ) was performed in advance. The changes upon polymerization were slight broadening of the characteristic band at $1662 \mathrm{~cm}^{-1}$ arising from the $-\mathrm{C}=\mathrm{C}$ - vibration of the ionic liquid monomer and relative decreases, due to the conversion of MIL to PIL with UV curing time.

The degree of conversion of monomeric ionic liquid to PIL was estimated by the intensity ratio $\mathrm{I}_{1662}$ and $\mathrm{I}_{1700}$ (used as reference band). Among the tested conditions, the polymerization reactions always succeed due to the MIL conversion was above $89 \%$ in all cases. Particularly, a maximum polymerization yield of $97 \%$ upon $2 \mathrm{~h}$ UV exposure time was registered, in agreement with previous results ${ }^{37}$. In order to assess PBI interactions with the PIL, FTIR spectra of the pure PBI microsieve and the composite PIL-SPBI are shown in Figure 4 5.B. For SPBI, the very broad peak located between 3700 and $2400 \mathrm{~cm}^{-1}$ corresponds to the free $\mathrm{N}-\mathrm{H}$ stretching, $\mathrm{N}-\mathrm{H} \cdots \mathrm{H}$ and $\mathrm{H} 2 \mathrm{O} \cdots \mathrm{H}$ hydrogen bond interactions.

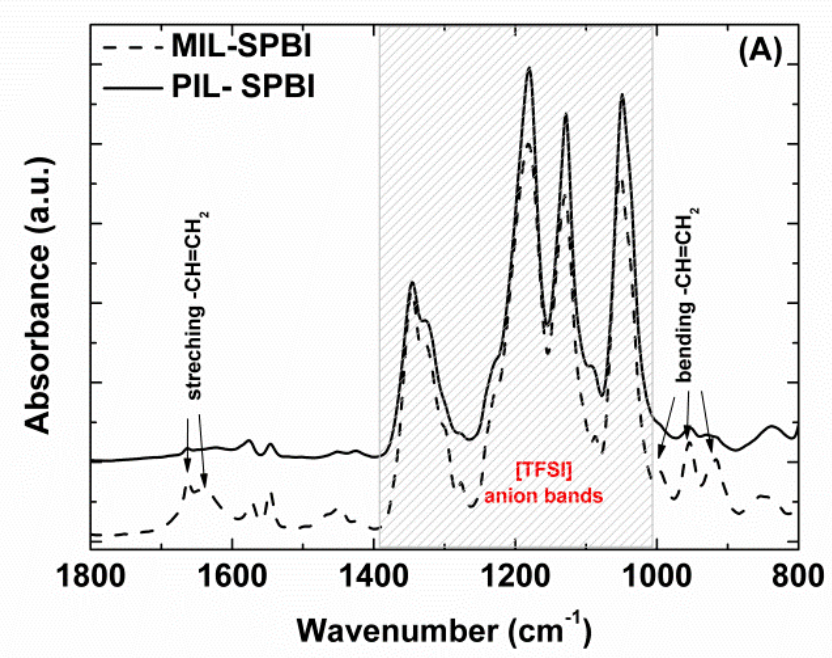




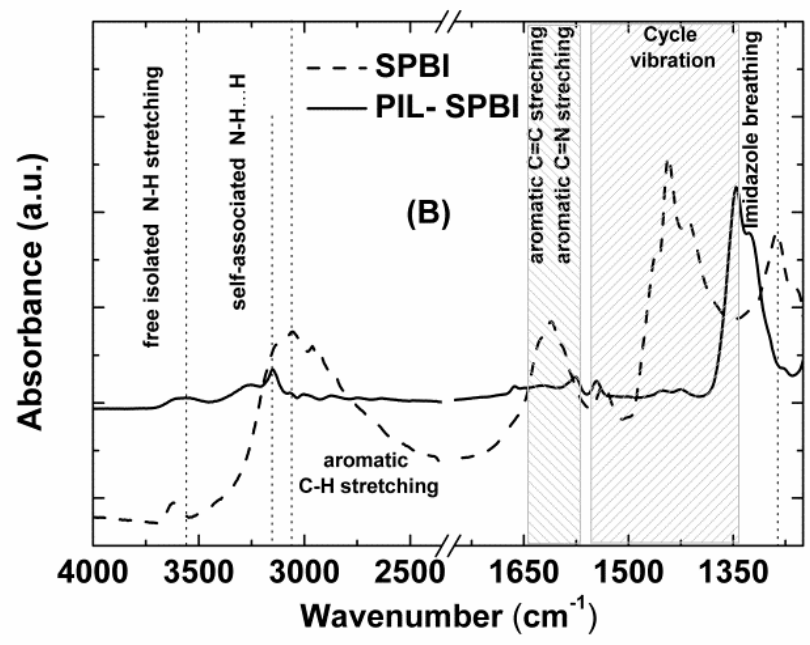

Figure 4 5. ATR-FTIR of: A) composite membranes before and after UV exposure; B) PBI microsieve with and without PIL electrolyte.

On the contrary, the PIL-SPBI spectrum in the region $3700-2400 \mathrm{~cm}^{-1}$ is composed of less intense bands at $3565 \mathrm{~cm}^{-1}$ attributed to stretching vibration of isolated non hydrogen bonds N-H group and $3270 \mathrm{~cm}^{-1}$ attributed to the stretching vibration of physisorbed $\mathrm{H} 2 \mathrm{O} \cdots \mathrm{H}$ hydrogen bonds. The relatively narrow peak centred at $3155 \mathrm{~cm}^{-1}$ is assigned to the self-associated hydrogen bonded N-H groups and the shoulder at $3059 \mathrm{~cm}^{-1}$ is due to the stretching modes of aromatics $\mathrm{CH}$ groups. In the 1800 and $1400 \mathrm{~cm}^{-1}$ region, the very broad band derived from aromatic $\mathrm{C}=\mathrm{C}$ and $\mathrm{C}=\mathrm{N}$ stretching modes is approximately centered at $1608 \mathrm{~cm}^{-1}$ for $\mathrm{SPBI}$ sample. Besides, the peaks corresponding to the in plane ring vibrations of substituted benzimidazole and imidazole ring breathing are clearly located at 1532, 1442 and $1280 \mathrm{~cm}^{-1}$ respectively. 
If the imine groups at the imidazole ring of the PBI are protonated ${ }^{25}$, frequency and intensity of some of the ring vibrations could decrease as it is observed in the composite PIL-SPBI sample. All these observations support the interactions between the imidazole ring of PBI and the protic PIL. In summary, the infiltration and polymerization of 1-H-3-vinylimidazolium bis(trifluoromethanesulfonyl)imide are affecting the PBI structure mainly due to: i) the hydrogen bonded $\mathrm{N}-\mathrm{H}$ groups increase vs. the free isolated ones; ii) the imine group from the imidazole ring is protonated; and iii) the benzimidazole vibration and imidazole breathing are notably suppressed.

\subsection{Proton Conductivity of PIL-SPBI electrolyte membranes}

Figure 5-6.A and Figure 5-6.B comparatively illustrate the Nyquist plots of PIL (40 Hz to 1.4 MHz) and PIL-SPBI (40 Hz to $110 \mathrm{MHz})$ membranes at $80{ }^{\circ} \mathrm{C}$ and $150{ }^{\circ} \mathrm{C}$, respectively. PILSPBI spectra show a compressed arc in the high frequency region and an inclined straight line indicating that an ion diffusion process plays the major role. A similar behavior has been observed for supported PIL on commercial alumina membranes (AnodiscTM) (see Fig S9 of the supplementary information). The small diameter of the semicircle indicates that the polarization resistance is almost negligible on PIL-SPBI membranes. Therefore, the electrolyte resistance can found by reading the real axis value at the intercept. As it was expected, the intersections shift to lower values as the temperature increases from $80^{\circ} \mathrm{C}$ to $150^{\circ} \mathrm{C}$. 

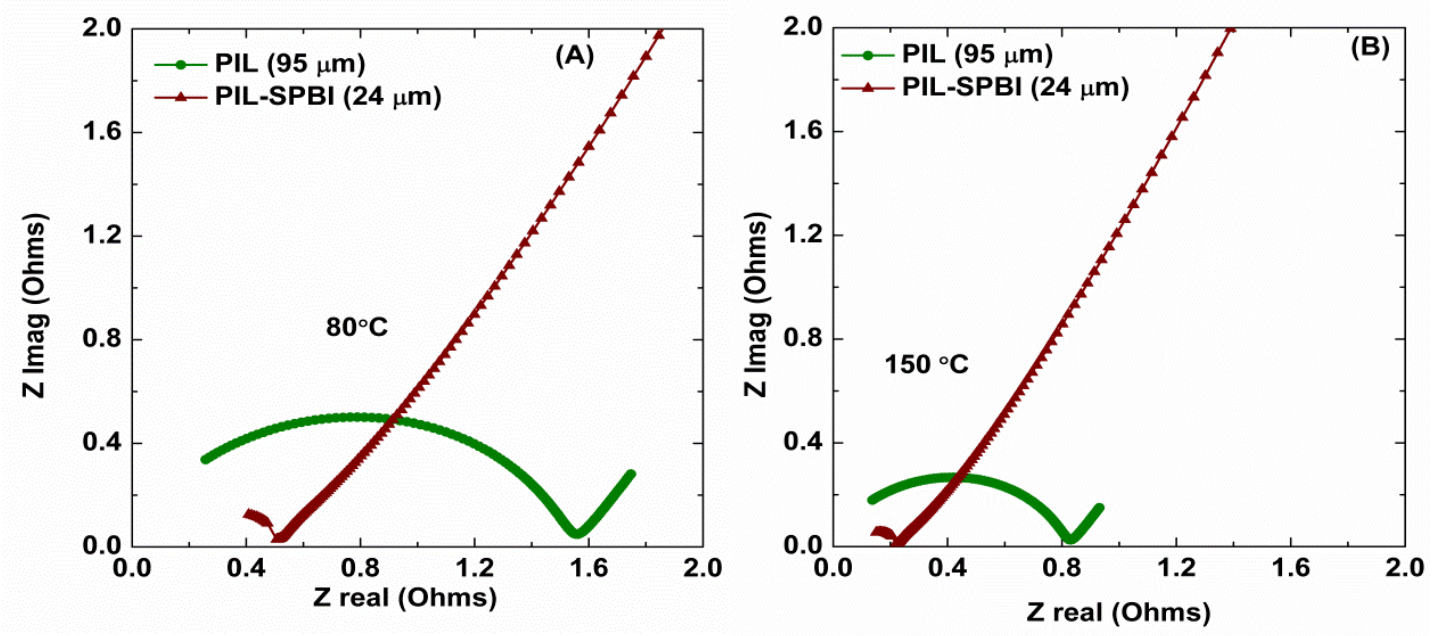

Figure 5 6. Nyquist Plot at (A) $80{ }^{\circ} \mathrm{C}$ and (B) $150{ }^{\circ} \mathrm{C}$ of pure PIL and P20-1.5-0\%CL.

Proton conductivity is considered to be a key property of HT PEMs. The proton conductivity of the PIL-SPBI composite electrolyte membranes as a function of temperature, from $70{ }^{\circ} \mathrm{C}$ up to $150{ }^{\circ} \mathrm{C}$ without humidification is shown in Figure $67 \mathrm{~A}$, where the conduction properties of pure and 1\% crosslinked PIL and phosphoric acid doped PBI microsieve (see Table 2) are also included for reference purposes. As it can be observed, all the conductivity values increases with temperature.

Pristine PBI microsieve has a negligible conductivity, i.e. $0.73 \mathrm{mS} \cdot \mathrm{cm}^{-1}$ at $150{ }^{\circ} \mathrm{C}$, and requires intrinsic conductors to facilitate proton transport. The "in situ" polymerization of MIL on SPBI yields to higher proton conductivity values compared to phosphoric acid doping of SPBI: 48.1 $\mathrm{mS} \cdot \mathrm{cm}^{-1}$ for $\mathrm{P} 20-1.5-0 \% \mathrm{CL}$ at $150{ }^{\circ} \mathrm{C}$ versus $9.5 \mathrm{mS} \cdot \mathrm{cm}^{-1}$ for $\mathrm{P} 20-1.5-\mathrm{PA}$ at $150^{\circ} \mathrm{C}$. It is wellknown that the mechanical strength of PBI diminishes upon phosphoric acid doping ${ }^{10-14}$. Thus, the pore filling followed by in-situ polymerization of MIL onto PBI microsieve leads to 
conducting phosphoric acid-free electrolyte membrane able to operate at $150{ }^{\circ} \mathrm{C}$ under anhydrous conditions.

The values exhibited by pure PILs are 6-7 folds higher than the registered for the PIL-SPBI composite: $330 \mathrm{mS} \cdot \mathrm{cm}^{-1}$ and $309 \mathrm{mS} \cdot \mathrm{cm}^{-1}$ for PIL and PIL-1\%CL vs. $48.1 \mathrm{mS} \cdot \mathrm{cm}^{-1}$ for P20-1.5$0 \% \mathrm{CL}$ at $150{ }^{\circ} \mathrm{C}$, respectively. Taking into account the porosity (36\%) of SPBI membrane and the bulk conductivity of PIL, conductivity value $\sim 118 \mathrm{mS} \cdot \mathrm{cm}^{-1}$ at $150^{\circ} \mathrm{C} 150{ }^{\circ} \mathrm{C}$ would be expected. Similar tendency, but more exacerbated, is observed for PIL confined on APA supports $70 \%$ in porosity with $100-200 \mathrm{~nm}$ in pore size. The registered conductivity value $\sim 11$ $\mathrm{mS} \cdot \mathrm{cm}^{-1}$ at $150^{\circ}$ (see Fig S9 of the supplementary information) is significantly less than the expected $\left(230 \mathrm{mS} \cdot \mathrm{cm}^{-1}\right.$ at $\left.150^{\circ} \mathrm{C}\right)$. The proton transport inhibition in ionic ${ }^{25}$ and poly-ionic ${ }^{44}$ liquids on PBI blends has been already described in the literature. Specially, when the ionic liquid is confined to block copolymer domains ${ }^{53}$, the hydrogen-bond structure of the ionic liquid is clearly affected; and, consequently the proton transport via vehicle and proton-hopping mechanisms. According to our infrared studies, shown in the previous section, specific interactions between the PIL and the PBI negatively affect the dynamics of effective charge carriers and the amount of diffusion-enhancing proton hopping.

The activation energy "Ea" values for proton transport were calculated from the slope of the Arrhenius type plot (see Figure 6-7B) in the intermediate range with temperature boundary conditions of 70 and $100^{\circ} \mathrm{C}$; and high temperature range from 100 to $150^{\circ} \mathrm{C}$, respectively. 

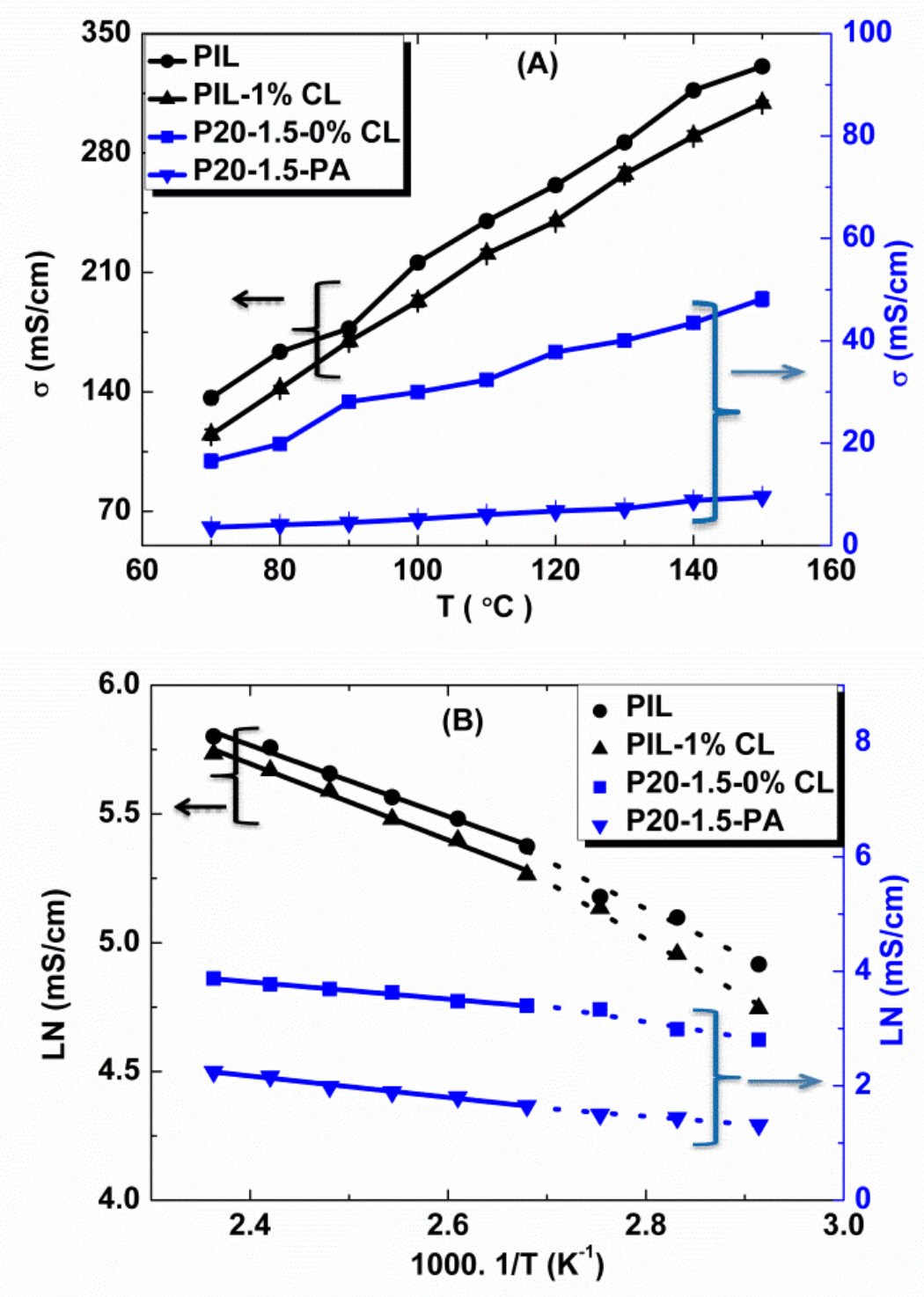

Figure 6 7. Conduction performance for pure PIL, PIL-1\%CL, P20-1.5-0\%CL and P20-1.5-0\% PA (Phosphoric acid) as a function of temperature under anhydrous conditions: A) Conductivity values; B) Arrhenius type plot.

In general, clear linear relationships in both temperature ranges are observed for all the tested membranes. Compared to the intermediate-temperature region, the estimated Ea values are lower 
when operating at 100 to $150^{\circ} \mathrm{C}$, as expected for anhydrous conditions. In particular for P20-1.5PA, the obtained values: $15.6 \mathrm{~kJ} \cdot \mathrm{mol}^{-1}\left(70-100^{\circ} \mathrm{C}\right)$ and $11.3 \mathrm{~kJ} \cdot \mathrm{mol}^{-1}\left(100-150^{\circ} \mathrm{C}\right)$, are within the typical range for PBI membranes with similar doping levels.

PIL electrolytes seem quite attractive for HT PEMs applications. In agreement with the previous findings by our group ${ }^{37}$, the lowest Ea values, i.e. $15.4 \mathrm{~kJ} \cdot \mathrm{mol}^{-1}\left(70-100^{\circ} \mathrm{C}\right)$ and $11.5 \mathrm{~kJ} \cdot \mathrm{mol}^{-1}$ $\left(100-150^{\circ} \mathrm{C}\right)$ correspond to PIL- $0 \% \mathrm{CL}$ due to the number of ion carriers and their mobility is the highest. For the PIL-1\%CL, the Ea values increase as expected, i.e. $18.5 \mathrm{~kJ} \cdot \mathrm{mol}^{-1}\left(70-100^{\circ} \mathrm{C}\right)$ and $12.3 \mathrm{~kJ} \cdot \mathrm{mol}^{-1}\left(100-150^{\circ} \mathrm{C}\right)$, due to the loss in long-range segmental motion at the expense of better mechanical properties (see section below).

Finally, the calculated Ea $\left(100-150^{\circ} \mathrm{C}\right)$ for PIL-SPBI composite, i.e. $12.4 \mathrm{~kJ}^{\mathrm{mol}}{ }^{-1}$ is similar to the exhibited by PIL infiltrated on randomly porous PBI support described in our previous work ${ }^{39}$, i.e. $13.6 \mathrm{~kJ} \cdot \mathrm{mol}^{-1}$. This could imply that the proton transport would be dominated by the same mechanism. Furthermore, these values are also similar to the reported for ionic liquid and PBI blends ${ }^{22,} 25,44$. On the basis of the Ea values for pure PIL membranes, $15.4 \mathrm{~kJ} \cdot \mathrm{mol}^{-1}$ (70$\left.100^{\circ} \mathrm{C}\right)$ and $11.5 \mathrm{~kJ} \cdot \mathrm{mol}^{-1}\left(100-150^{\circ} \mathrm{C}\right)$, it can be concluded that the PIL-SPBI led to a higher Ea $\left(22.8 \mathrm{~kJ} \cdot \mathrm{mol}^{-1}\left(70^{\circ}-100^{\circ} \mathrm{C}\right)\right.$ due to the hopping transport and vehicular inhibition.

\subsection{Thermal and Mechanical Properties of cross-linked PIL-SPBI electrolyte membranes}

The final objective of this work is obtaining PEMs for improving physicochemical, mainly thermal and mechanical, and electrochemical properties for applicability at temperatures above $100{ }^{\circ} \mathrm{C}$ under dry conditions. For such purposes, the PIL electrolyte modification by crosslinking with divinylbenzene has been chosen to improve its fluidity behavior and mechanical strength. The cross linker content boundary conditions selected for this study, from 0.2 up to $1 \mathrm{~mol}$. \%, have been stablished on the results from our previous work ${ }^{37}$ where molar percentages values up 

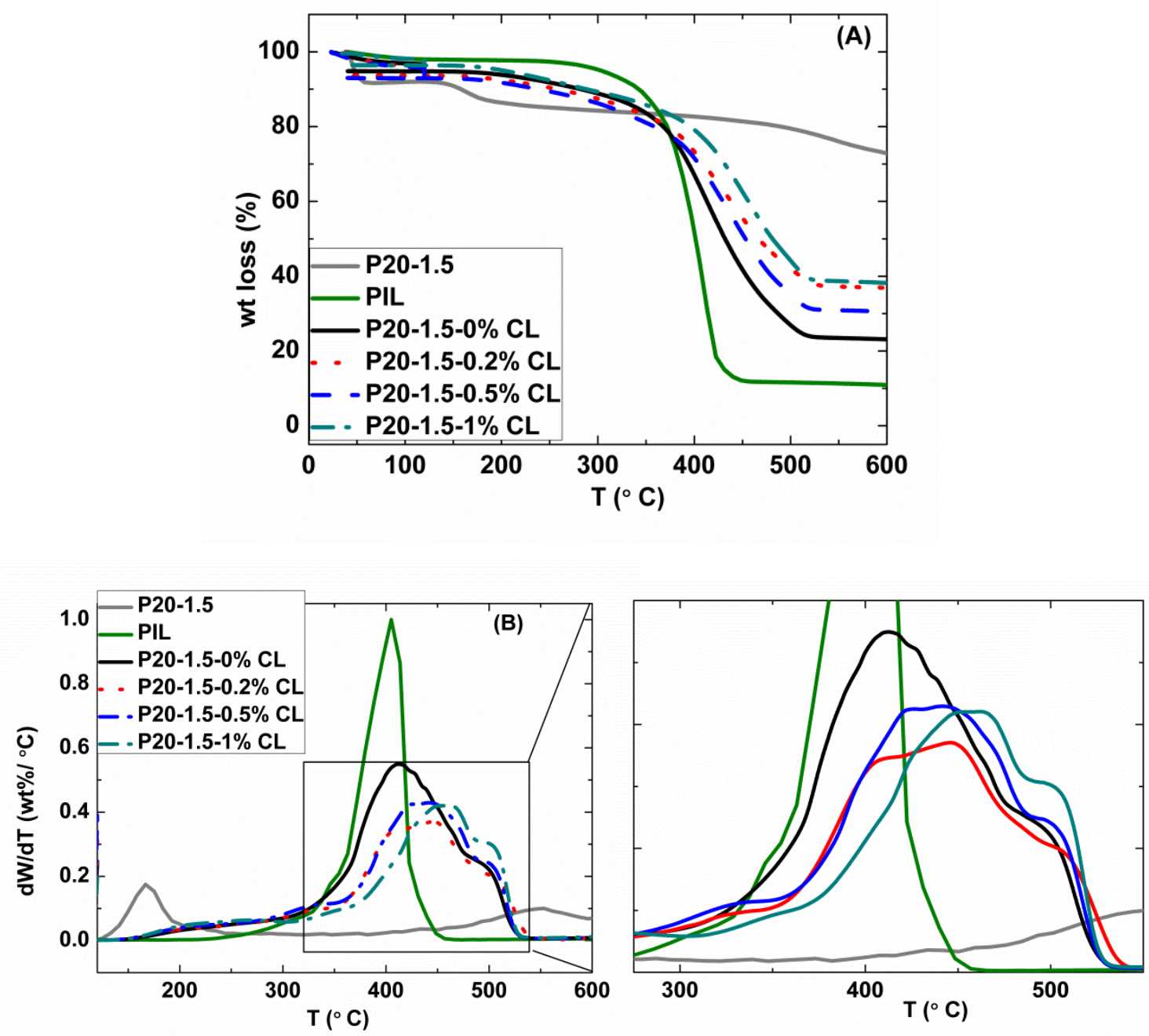

Figure 7 8. A) TGA and B) DTG thermograms of PIL based membranes (pure PIL and PBI microsieve also represented for comparison purposes). (Delete $3^{\text {rd }}$ figure)

to 7.2 mol.\% were investigated. The TGA and DTG thermograms are shown in Figure 7 8.A and Figure 7 8.B respectively. The TGA curve of PIL-SPBI membranes indicates three main reaction stages. 
An initial weight loss over the temperature range of $50-200{ }^{\circ} \mathrm{C}$ (particularly noticeable for pristine PBI microsieve), a second one over $300-540{ }^{\circ} \mathrm{C}$ (particularly noticeable for pure PIL) and a third one beyond $600^{\circ} \mathrm{C}$ were noticed. The first weight loss is ascribed to the loss of absorbed water molecules and to the presence of traces of the photoinitiator (whose first onset temperature occurs at around $200^{\circ} \mathrm{C}$ ).

Pure SPBI showed maximum weight loss (13.6\%) in this region due to its hydrophilic nature (see Table S4). On PIL-SPBI samples, the weight loss values are $6.1 \%, 7.3 \%, 8.2 \%$ and $4.7 \%$ for P20-1.5-0\%CL, P20-1.5-0.2\%CL, P20-1.5-0.5\%CL and P20-1.5-1\%CL respectively.

In particular, very low weight losses, $0.8 \%-1.5 \%$ have been observed in all of the composite PILSPBI membranes within the $150-200{ }^{\circ} \mathrm{C}$ temperature range. The second and most noticeable weight loss was due to the decomposition of the PIL. It is centered at around $400-450{ }^{\circ} \mathrm{C}$ (vs. $405{ }^{\circ} \mathrm{C}$ for pure PIL sample). The PIL degradation takes place within the range of $300-540{ }^{\circ} \mathrm{C}$. Our study showed that the cross-linked samples started to decompose later and as a consequence the second peak become broader and shifted to higher temperature as cross linker content increases. This effect is in agreement with an effective crosslinking.

Unlike the pure PIL specimen, a shoulder at around $490-505{ }^{\circ} \mathrm{C}$ was depicted on supported PIL samples. The authors hypothesize that this event is related to the interactions between PIL and PBI support, already identified by FTIR (see Figure 4 5). Finally, the third weight loss, with an onset temperature above $600{ }^{\circ} \mathrm{C}$ for the PIL-SPBI composites, was attributed to the decomposition of the PBI backbone.

Table 4 summarizes the mechanical properties of the electrolyte membranes prepared for this work. One of the vital requirements of PEM for practical operation relies on the mechanical stability. 
Table 4. Mechanical properties of the electrolyte membranes prepared for this work at room conditions.

\begin{tabular}{cccc}
\hline Membrane & Young Modulus & Tensile Stress & Tensile strain \\
$(\mathrm{GPa})$ & $(\mathrm{MPa})$ & $(\%)$ \\
\hline PIL* & $0.21 \pm 0.03$ & - & $7.1 \pm 0.281$ \\
P20-1.5-0\%CL & $1.8 \pm 0.327$ & $4.6 \pm 1.085$ & $5.8 \pm 0.163$ \\
P20-1.5-0.2\%CL & $2.2 \pm 0.047$ & $6.0 \pm 0.374$ & $4.5 \pm 1.212$ \\
P20-1.5-0.5\%CL & $2.4 \pm 0.071$ & $8.4 \pm 0.173$ & $2.5 \pm 0.321$ \\
P20-1.5-1\%CL & $2.6 \pm 0.072$ & $10.0 \pm 2.161$ & $39.7 \pm 9.8$ \\
\hline AsymPBI** & $1.4 \pm 0.18$ & $46.9 \pm 3.2$ & \\
\hline
\end{tabular}

* Data from ${ }^{37,39} ; * *$ Data from Asymmetric PBI membrane $83 \%$ porosity $^{48}$

Particularly, high storage modulus, and low swelling values are desirable ${ }^{54}$. In general, the mechanical properties of porous membranes depend on many factors e.g. the porosity, distribution, size and shape of the pores ${ }^{48}$. Although pure PILs electrochemically outperform PIL-SPBI composites; the mechanical properties reveal insufficient for FC applications, i.e. the Young's modulus measured by incremental stretch relaxation tests is $215 \mathrm{MPa}^{37}$. The strainstress curves of the prepared PIL-SPBI membranes with and without cross linker are shown in Figure 89 (move to supporting information, named as Fig S10). 


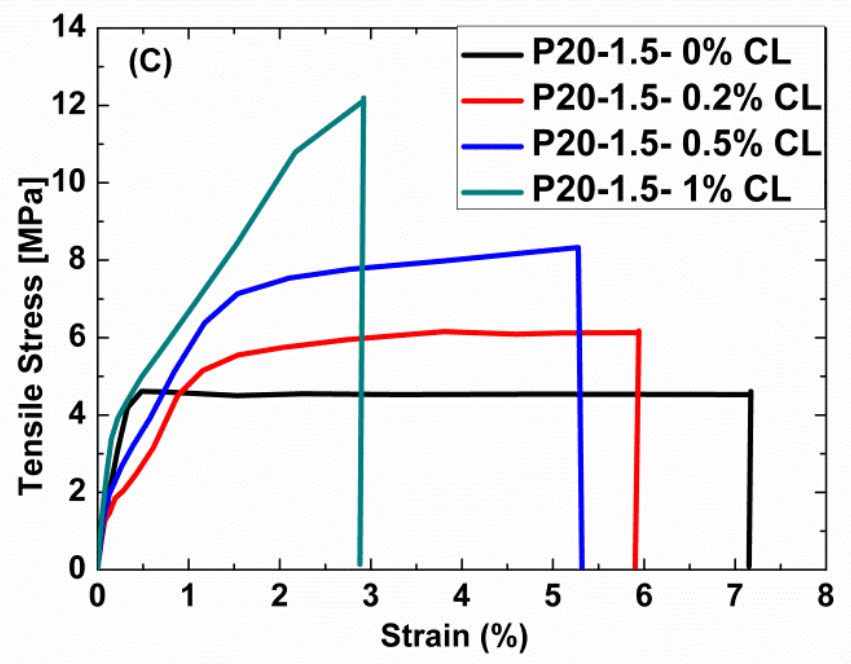

Figure 9. Stress-strain curve of PH-SPBI membranes at room conditions move to supporting information, named as Fig S10.

As predictable, the Young modulus values of the composite membranes are approximately one order of magnitude higher due to the structural support provided by the PBI microsieve $36 \%$ in porosity. It is noteworthy to underline that the mechanical properties of reinforced PIL on randomly porous PBI support $85 \%$ in porosity, described in our previous work ${ }^{39}$, is comparatively lesser: $0.2 \mathrm{GPa}$ as Young Modulus and 1.3 $\mathrm{MPa}$ as tensile strength. Concerning cross linked PIL-SPBI membranes, the moduli and strength increased with the increasing amount of CL agent ${ }^{44}$. The opposite behaviour is for the $\%$ elongation at break, due to the glassy nature may be increased with divinylbenzene due to a restriction of the polymer chain motion in the cross-linked network. Figure2-c illustrates the suggested PIL structure for poly[1-(3Himidazolium)ethylene]bis(trifluoromethanesulfonyl)imide. Furthermore, Figure 12.B describes the loss in long-range segmental motion as polymer chains become more restricted due to 
crosslinking effect between polycationic chains ${ }^{39}$. In summary, a moderate enhancement in both thermal and mechanical stability is attained by crosslinking of the polycationic network.

\subsection{Electrochemical Properties of cross-linked PIL-SPBI electrolyte membranes}

In order to investigate the tradeoff between thermal/mechanical and electrochemical properties of cross-linked samples, the influence of CL (divinylbenzene) on the proton conductivity was carefully studied. Thus, the conduction performance of PIL-SPBI membranes as a function of CL content, from $0 \%$ to $1 \%$ mol, was investigated up to $150{ }^{\circ} \mathrm{C}$ under anhydrous conditions. As shown in Figure 9, the appearance of the as prepared membranes before and after the electrochemical characterization remains unaltered.

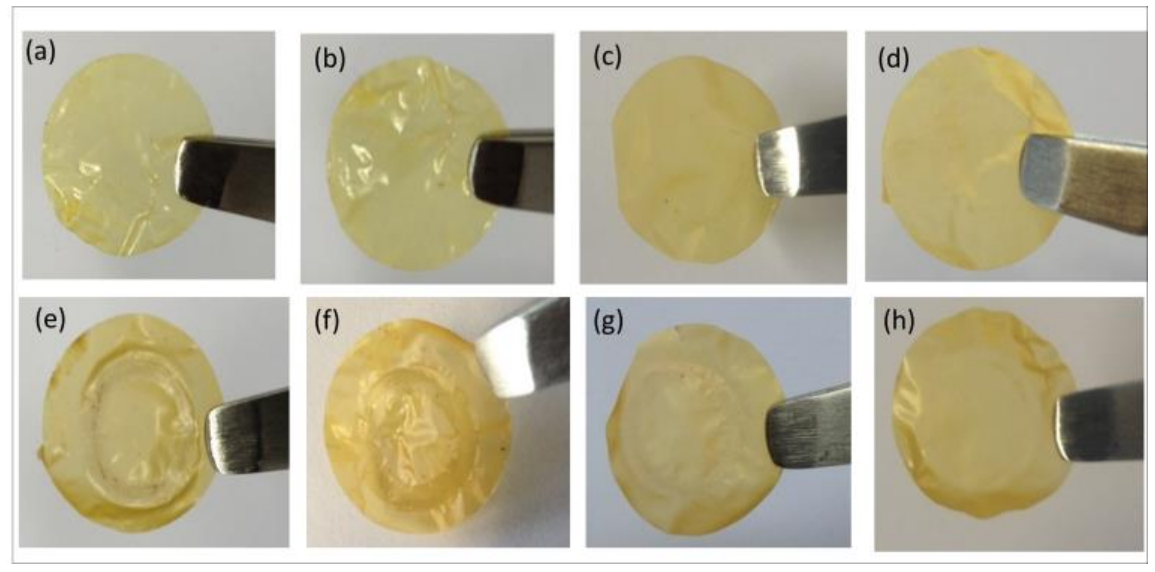

Figure 9. Appearance of PIL-SPBI based membranes. Top: Fresh membranes, (a) P20-1.50\%CL; (b) P20-1.5-0.2\%CL; (c) P20-1.5-0.5\%CL; (d) P20-1.5-0\%CL; Bottom: Used membranes at $150^{\circ} \mathrm{C}$, (e) P20-1.5-0\%CL; (f) P20-1.5-0.2\%CL; (g) P20-1.5-0.5\%CL; (h) P20$1.5-1 \%$ CL. 
The temperature dependence of proton conductivity, for the cross linked PIL-SPBI membranes, is shown in Figure 10.A. As expected for all the membranes, the proton conductivity increased with temperature in the studied range.
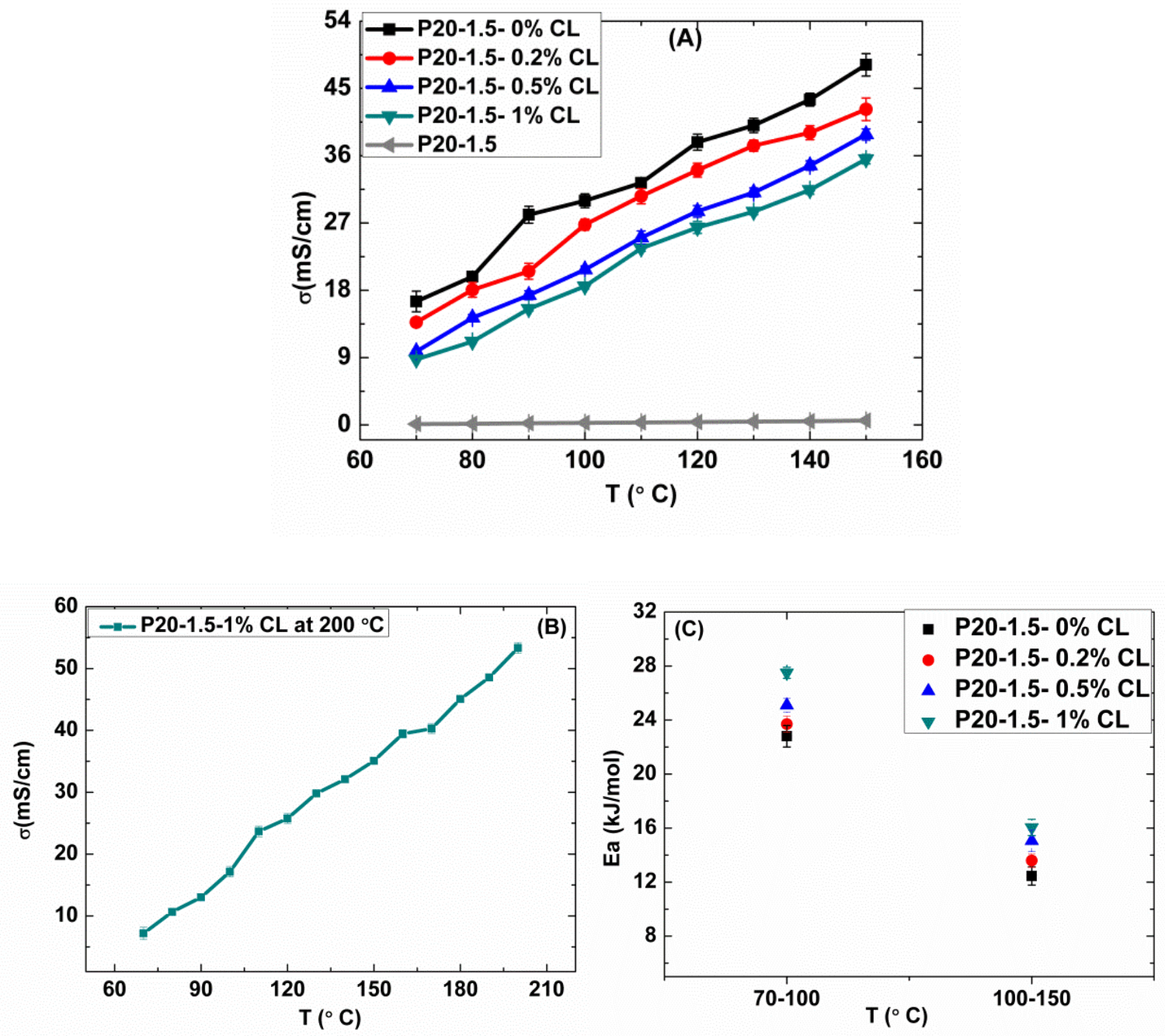

Figure 10. Conductivity measurements of PIL-SPBI membrane as a function of CL content: A) conduction performances; B) variation of Ea of composite PIL-SPBI membranes at different temperature windows. 
The maximum conductivity of $\mathrm{P} 20-1.5-0.2 \% \mathrm{CL}$ membrane is $42.2 \mathrm{mS} \cdot \mathrm{cm}^{-1}$ at $150{ }^{\circ} \mathrm{C}$, lower than the membrane without $\mathrm{CL}\left(48.1 \mathrm{mS} \cdot \mathrm{cm}^{-1}\right.$ at $\left.150^{\circ} \mathrm{C}\right)$. The conductivity dropped slightly as the $\mathrm{CL}$ amount increased from 0.2 to $0.5 \mathrm{~mol}$ \% which reflects the crosslinking degree of the divinylbenzene in the chemical structure of the PIL-SPBI membrane. A further decrease in conductivity in PIL-SPBI membrane is observed as the CL amount increased $0.5 \%$ to $1 \mathrm{~mol}$. $\%$. The maximum conductivity of $\mathrm{P} 20-1.5-0.5 \% \mathrm{CL}$ and $\mathrm{P} 20-1.5-1 \% \mathrm{CL}$ membranes is 38.8 and 35.5 $\mathrm{mS} \cdot \mathrm{cm}^{-1}$ respectively at $150{ }^{\circ} \mathrm{C}$. The above results mean that the mobility of proton is affected by the CL amount. This indicates that even minor amounts of CL hinders (Figure 11.B) the proton mobility due to the loss in the long-range segmental movement of polymeric chains. Besides, divinylbenzene CL is a weak electrochemical in nature. On the other hand, the thermal and mechanical properties decreased upon decreasing the CL amount (see Table 4).

In addition, conductivity measurements were prolonged up to $50 \mathrm{~h}$ for durability purposes (see Table 2). Therefore, as soon as the membrane conductivity was firstly estimated according to Figure 10 protocol, it was kept for $50 \mathrm{~h}$ at $150{ }^{\circ} \mathrm{C}$. The maximum decline in conductivity was 9.6\%, 8.9\%, 6.5\% and 1.5\% for P20-1.5-0\%CL, P20-1.5-0.2\%CL, P20-1.5-0.5\%CL, and P20$1.5-1 \% \mathrm{CL}$ respectively. Figure 9 shows the pictures of the prepared PIL-SPBI membranes before and after conductivity measurements. Before testing, see Figure 9: a-d, all membrane surfaces appeared relatively light yellow which indicates a successful polymerization. The level of shininess between the membrane's two sides decreased with the cross linker amount. All the membranes were free standing films and handled without any difficulty; although the crosslinked PIL-SPBI membranes behave mechanically better than P20-1.5-0\%CL. Upon durability test, see Figure 9: e-h, the membrane surface revealed unaffected in terms of cracks and defects. However, the membrane surface in contact with the measuring annular electrodes is clearly 
drawn on P20-1.5-0\%CL and P20-1.5-0.2\%CL samples in accordance to their comparatively lower Young modulus value (see Table 4).

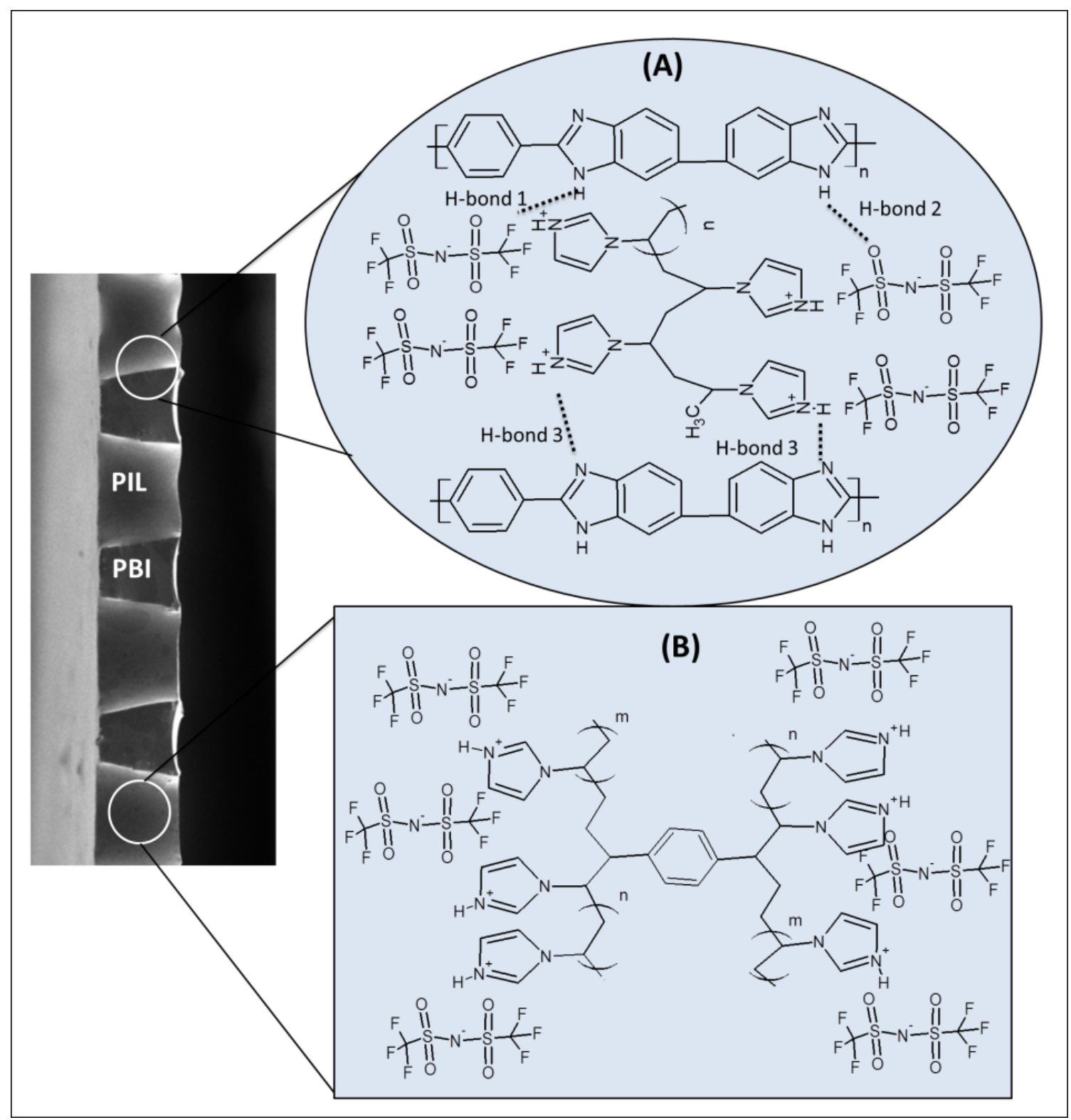

Figure 11. Postulated proton transport mechanism on PIL-SPBI membranes at: A) the surface layer near the pore-wall surface); B) the inner layer (far away from the pore-wall surface). 
As a result, the optimal formulation as trade-off between proton transport and mechanical properties corresponds to P20-1.5-1\%CL (see graphical abstract). Figure 10.B S 11 shows the conduction performance of $\mathrm{P} 20-1.5-1 \% \mathrm{CL}$ from $70^{\circ} \mathrm{C}$ up to $200{ }^{\circ} \mathrm{C}$. The registered proton conductivity under anhydrous conditions was $53.3 \mathrm{mS} \cdot \mathrm{cm}^{-1}$ at $200^{\circ} \mathrm{C}$.

In order to elucidate the effects of PIL crosslinking in the PIL-SPBI membranes, the activation energy for proton transport was evaluated. The analysis of the apparent Arrhenius-type activation energies (Ea) for proton transport in two different temperature windows are presented in supporting information (Fig. S10 S12 and Table S5). All the tested showed similar temperature dependence conductivity (see Figure 10.A); which indicates a similar proton transport mechanism. Figure 11.C 10.B shows the Ea values as a function of CL content for the two different temperature windows.

The calculated Ea values of all cross linked membranes at $100^{\circ}-150^{\circ} \mathrm{C}$ are relatively lower than the Ea values obtained at $70^{\circ}-100^{\circ} \mathrm{C}$ due to the PIL's fluidity increases.

According to the Nyquist plot registered for all the PIL-SPBI composites, the conduction pattern is dominated by the fluidity of PIL chains confined in the macropores of the PBI microsieve. As it was expected, the Ea for proton transport increases with the $\%$ of cross-linker agent due to the loss in long-range segmental motion. The activation energy obtained ranges from 23.7, 25.0 and $27.4 \mathrm{~kJ} \cdot \mathrm{mol}^{-1}$ at $70^{\circ}-100{ }^{\circ} \mathrm{C}$ and $13.6,15.0$ and $16.0 \mathrm{~kJ} \cdot \mathrm{mol}^{-1}$ at $100^{\circ}-150{ }^{\circ} \mathrm{C}$ for P20-1.5$0.2 \% \mathrm{CL}, \mathrm{P} 20-1.5-0.5 \% \mathrm{CL}$, and P20-1.5-1\%CL respectively. These values are slightly higher than those exhibited by P20-1.5-0\%CL, i.e. $22.8 \mathrm{~kJ} \cdot \mathrm{mol}^{-1}\left(70^{\circ}-100{ }^{\circ} \mathrm{C}\right)-12.4 \mathrm{~kJ} \cdot \mathrm{mol}^{-1}\left(100^{\circ}-150\right.$ $\left.{ }^{\circ} \mathrm{C}\right)$.

When comparing with Ea data from unsupported PIL membranes, the lowest value corresponds to pure PIL: $15.4 \mathrm{~kJ} \cdot \mathrm{mol}^{-1}$ at $70^{\circ}-100{ }^{\circ} \mathrm{C}$ and $11.5 \mathrm{~kJ} \cdot \mathrm{mol}^{-1}$ at $100^{\circ}-150{ }^{\circ} \mathrm{C}$; followed by PIL- 
$1 \% \mathrm{CL}: 18.5 \mathrm{~kJ} \cdot \mathrm{mol}^{-1}$ at $70^{\circ}-100^{\circ} \mathrm{C}$ and $12.3 \mathrm{~kJ} \cdot \mathrm{mol}^{-1}$ at $100^{\circ}-150^{\circ} \mathrm{C}$. Hence, our hypothesis for the proton transport inhibition relies on the hydrogen bonding interactions between the electrolyte and the confining PBI matrix (see Figure 11.A) at the pore-wall surface. The reactive 1H-benzimidazol group from PBI would interact with oxygen (H-bond 1) and fluorine (H-bond 2) atoms of free [TFSI-] anions. In addition, hydrogen bonding interactions (H-bond3) could be generated from the proton of the poly cation and the imine group from the PBI backbone. The FTIR and TGA analyses also support this postulation.

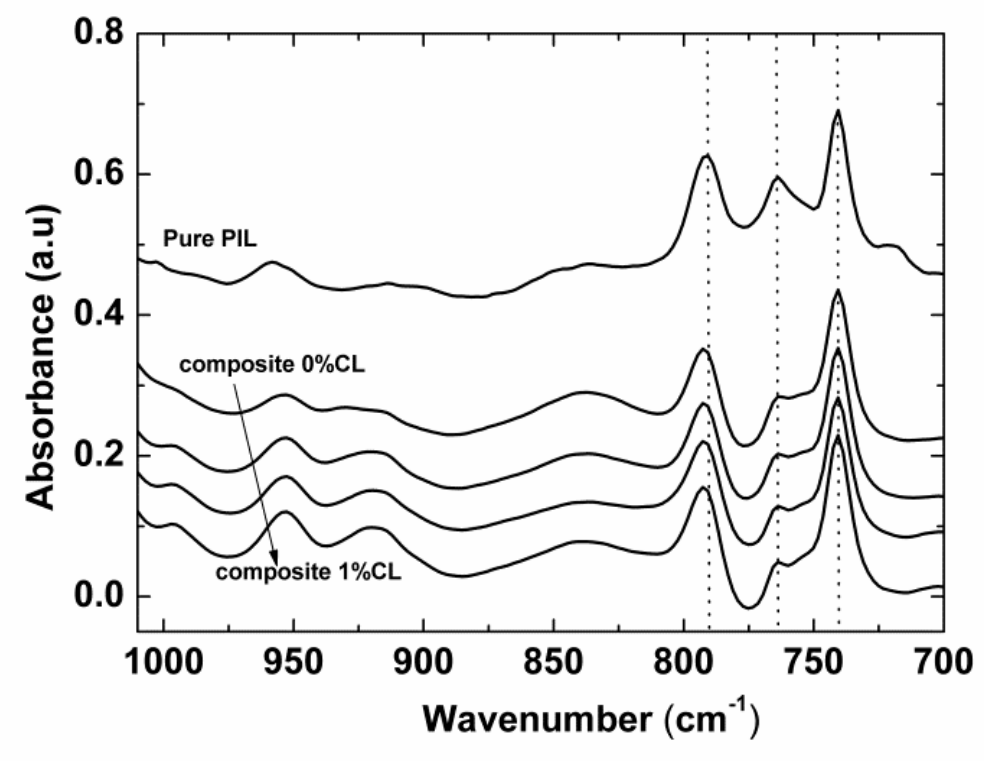

Figure 12. ATR-FTIR of PIL-SPBI composite membranes as a function of the CL content (pure PIL is also included for comparison.

Indeed, Figure 12 presents comparative FTIR spectra obtained from the PIL-SPBI composites to distinguish significant differences due to crosslinking and PBI confinement. Comparison of spectra for PIL-SPBI composites reveals that they are almost indistinguishable. However, the 
appearance change in the peak centered at around $762 \mathrm{~cm}^{-1}$, assigned to the vibration of SNS from [TFSI], when compared to pure PIL, is likely due to the hydrogen-bond structure previously described. Similar interactions have been proposed for PBI with 1-hexyl-3methylimidazolium trifluoromethanesulfonate ${ }^{22}$ and with the poly(diallyl dimethyl ammonium trifluoride methane sulphonate) ${ }^{44}$; and for doped polyaniline films with 1-ethyl-3methylimidazolium trifluoromethanesulfonate ionic liquid ${ }^{55}$. Summarizing, the properties of poly [1-(3H-imidazolium)ethylene] bis(trifluoromethanesulfonyl)imide in the surface layer would be affected by the substrate wall-fluid interactions. These interactions slow down the proton transport dynamics and so the viscosity in the surface layer is expected to be high ${ }^{56}$.

On the contrary, the properties of molecules inside the inner layers would be only controlled by the interactions among the polycationic chains and the free anions (see Figure 11.B). As a consequence, the viscosity in this layer is expected to be lower; and correspondingly, higher proton conductivity. Such a description would be reasonably accepted for the macroporous support herein studied with $15-17 \mu \mathrm{m}$ as pore size. However, the PIL in the confined geometry experimentally behaves clearly different.

\section{CONCLUSIONS}

In this work, highly conductive proton exchange electrolyte membranes capable to operate at temperatures up to $200{ }^{\circ} \mathrm{C}$ have been successfully prepared. The fabrication process involves the infiltration of 1-H-3-Vinyl imidazolium bis(trifluoromethanesulfonyl) Imide solution into straight porous PBI support ( $36 \%$ in porosity and $17 \mu \mathrm{m}$ in pore size) obtained by microtransfer moulding technique followed by in situ UV polymerization of the ionic moieties. The developed flexible electrolyte membranes, less than $25 \mu \mathrm{m}$ thick, are composed of straight poly-ionic liquid 
microchannel circa $15 \mu \mathrm{m}$ in diameter embedded in the polybenzimidazole skeleton. The hydrogen bonding interactions between the benzimidazole unit of the SPBI support and the protic PIL network impart thermal and mechanical stability to the electrolyte membrane at the expense of proton transport inhibition. Similarly, the addition of divinylbenzene cross linker to the imidazolium based polymeric ionic liquid improves the endurance behavior of the electrolytes above $120^{\circ} \mathrm{C}$. In general, all the composite PIL-SPBI membranes, with and without cross-linker, exhibit adequate thermal, mechanical, and electrochemical properties for PEM applications up to $150{ }^{\circ} \mathrm{C}$ under anhydrous conditions in absence of mineral acid molecules. Among the tested, the sample with 1 mol.\% of cross linker content (referred to the PIL) outstands as the optimal tradeoff between proton transport $\left(53.3 \mathrm{mS} \cdot \mathrm{cm}^{-1}\right.$ at $\left.200^{\circ} \mathrm{C}\right)$ and mechanical properties (Young modulus and Tensile-stress values are 2.6 GPa and 10.7 MPa respectively). This novel fabrication approach is very promising for the development of high temperature flexible electrolytes with excellent proton conductivities for electrochemical devices.

\section{ASSOCIATED CONTENT}

\section{Supporting Information.}

SU-8 masters dimensions and the procedure for Fabrication of PDMS moulds. Rheological properties of pure MIL and MIL-acetone solution. SEM image of heterogeneous PIL-PBI membrane and, homemade device for the MIL infiltration on the PBI microsieve. Nyquist plot of P20-1.5-1\%CL and Table of Resistance values obtained from Nyquist plot. The effect of PBI concentration in the final DMAc solution.SEM image of P20-2 sample prepared from casting of P20 PDMS mould, conditions for the Casting of P15 PDMS mould and SEM images of P15-1.3 microsieves obtained from P15 mould. Thermal analyses of MIL, PIL and PIL-1\%CL, 
Fabrication of pure PIL and PIL-1\%CL procedure and Home-made Teflon plates for the casting of pure PIL membranes. Contact angle measurements of wetting ionic liquids on PBI surfaces. and ATR-FTIR analysis of ionic liquid based films as a function of UV exposure time. Nyquist plots of PIL supported on commercial track-etched AnodiscTM membranes. Stress-strain curve of PIL-SPBI membranes. Conduction performance of P20-1.5-1\%CL up to $200^{\circ} \mathrm{C}$. Arrhenius plot of conductivity data for crosslinked SPBI/PIL membranes. Table of Activation energy values of PIL-SPBI electrolyte membranes as a function of crosslinking. This information is available free of charge via the Internet at http://pubs.acs.org.

\section{AUTHOR INFORMATION}

\section{Corresponding Author}

*E-mail: mapina@unizar.es; Tel: +34 976761155

\section{ACKNOWLEDGMENT}

The authors would like to acknowledge the financial support from the Government of Aragon and the Education, Audiovisual and Culture Executive Agency (EU-EACEA) within the EUDIME - "Erasmus Mundus Doctorate in Membrane Engineering" program (FPA 2011-0014, SGA 2012-1719, http://eudime.unical.it). CIBER-BBN is an initiative funded by the VI National R\&D\&i Plan 2008-2011financed by the Instituto de Salud Carlos III with the assistance of the European Regional Development Fund. Authors acknowledge the LMA-INA for offering access to their instruments and expertise". The authors would like to thank Dr. Celine Pochat-Bohatier and Sakthivel Nagarajan (IEM, Montpellier) for their help in the mechanical stability experiments.

\section{REFERENCES}


1. Debe, M. K., Electrocatalyst approaches and challenges for automotive fuel cells. Nature 2012, 486 (7401), 43-51.

2. Thounthong, P.; Raël, S.; Davat, B., Energy management of fuel cell/battery/supercapacitor hybrid power source for vehicle applications. Journal of Power Sources 2009, 193 (1), 376-385.

3. Bose, S.; Kuila, T.; Nguyen, T. X. H.; Kim, N. H.; Lau, K.-t.; Lee, J. H., Polymer membranes for high temperature proton exchange membrane fuel cell: Recent advances and challenges. Progress in Polymer Science 2011, 36 (6), 813-843.

4. Hogarth, W. H. J.; Diniz da Costa, J. C.; Lu, G. Q., Solid acid membranes for high temperature $\left(i 140^{\circ} \mathrm{C}\right)$ proton exchange membrane fuel cells. Journal of Power Sources 2005, $142(1-2), 223-237$.

5. Li, Q.; He, R.; Jensen, J. O.; Bjerrum, N. J., Approaches and Recent Development of Polymer Electrolyte Membranes for Fuel Cells Operating above $100{ }^{\circ} \mathrm{C}$. Chemistry of Materials 2003, 15 (26), 4896-4915.

6. Shao, Y.; Yin, G.; Wang, Z.; Gao, Y., Proton exchange membrane fuel cell from low temperature to high temperature: Material challenges. Journal of Power Sources 2007, 167 (2), 235-242.

7. Li, Q.; Jensen, J. O.; Savinell, R. F.; Bjerrum, N. J., High temperature proton exchange membranes based on polybenzimidazoles for fuel cells. Progress in Polymer Science 2009, 34 (5), 449-477.

8. Asensio, J. A.; Sanchez, E. M.; Gomez-Romero, P., Proton-conducting membranes based on benzimidazole polymers for high-temperature PEM fuel cells. A chemical quest. Chemical Society reviews 2010, 39 (8), 3210-39.

9. $\quad$ Chandan, A.; Hattenberger, M.; El-kharouf, A.; Du, S.; Dhir, A.; Self, V.; Pollet, B. G.; Ingram, A.; Bujalski, W., High temperature (HT) polymer electrolyte membrane fuel cells (PEMFC) - A review. Journal of Power Sources 2013, 231, 264-278.

10. Li, Q.; He, R.; Jensen, J. O.; Bjerrum, N. J., PBI-Based Polymer Membranes for High Temperature Fuel Cells - Preparation, Characterization and Fuel Cell Demonstration. Fuel Cells 2004, 4 (3), 147-159.

11. Li, Q.; He, R.; Berg, R. W.; Hjuler, H. A.; Bjerrum, N. J., Water uptake and acid doping of polybenzimidazoles as electrolyte membranes for fuel cells. Solid State Ionics 2004, 168 (12), 177-185.

12. Ma, Y. L.; Wainright, J. S.; Litt, M. H.; Savinell, R. F., Conductivity of PBI Membranes for High-Temperature Polymer Electrolyte Fuel Cells. Journal of The Electrochemical Society 2004, 151 (1), A8.

13. He, R.; Li, Q.; Bach, A.; Jensen, J.; Bjerrum, N., Physicochemical properties of phosphoric acid doped polybenzimidazole membranes for fuel cells. Journal of Membrane Science 2006, 277 (1-2), 38-45.

14. Lobato, J.; Cañizares, P.; Rodrigo, M. A.; Linares, J. J.; Aguilar, J. A., Improved polybenzimidazole films for H3PO4-doped PBI-based high temperature PEMFC. Journal of Membrane Science 2007, 306 (1-2), 47-55.

15. Galbiati, S.; Baricci, A.; Casalegno, A.; Marchesi, R., Degradation in phosphoric acid doped polymer fuel cells: A $6000 \mathrm{~h}$ parametric investigation. International Journal of Hydrogen Energy 2013, 38 (15), 6469-6480. 
16. Qi, Z.; Buelte, S., Effect of open circuit voltage on performance and degradation of high temperature PBI-H3PO4 fuel cells. Journal of Power Sources 2006, 161 (2), 1126-1132.

17. MacFarlane, D. R.; Forsyth, M.; Howlett, P. C.; Pringle, J. M.; Sun, J.; Annat, G.; Neil, W.; Izgorodina, E. I., Ionic Liquids in Electrochemical Devices and Processes: Managing Interfacial Electrochemistry. Accounts of Chemical Research 2007, 40 (11), 1165-1173.

18. Armand, M.; Endres, F.; MacFarlane, D. R.; Ohno, H.; Scrosati, B., Ionic-liquid materials for the electrochemical challenges of the future. Nat Mater 2009, 8 (8), 621-629.

19. Díaz, M.; Ortiz, A.; Ortiz, I., Progress in the use of ionic liquids as electrolyte membranes in fuel cells. Journal of Membrane Science 2014, 469, 379-396.

20. MacFarlane, D. R.; Tachikawa, N.; Forsyth, M.; Pringle, J. M.; Howlett, P. C.; Elliott, G. D.; Davis, J. H.; Watanabe, M.; Simon, P.; Angell, C. A., Energy applications of ionic liquids. Energy \& Environmental Science 2014, 7 (1), 232-250.

21. Ye, H.; Huang, J.; Xu, J. J.; Kodiweera, N. K. A. C.; Jayakody, J. R. P.; Greenbaum, S. G., New membranes based on ionic liquids for PEM fuel cells at elevated temperatures. Journal of Power Sources 2008, 178 (2), 651-660.

22. Wang, J. T.-W.; Hsu, S. L.-C., Enhanced high-temperature polymer electrolyte membrane for fuel cells based on polybenzimidazole and ionic liquids. Electrochimica Acta 2011, 56 (7), 2842-2846.

23. Hernández Carrillo, R.; Suarez-Guevara, J.; Torres-González, L. C.; Gómez-Romero, P.; Sánchez, E. M., Incorporation of benzimidazolium ionic liquid in proton exchange membranes ABPBI-H3PO4. Journal of Molecular Liquids 2013, 181, 115-120.

24. Liu, S.; Zhou, L.; Wang, P.; Zhang, F.; Yu, S.; Shao, Z.; Yi, B., Ionic-liquid-based proton conducting membranes for anhydrous $\mathrm{H} 2 / \mathrm{Cl} 2$ fuel-cell applications. ACS applied materials \& interfaces 2014, 6 (5), 3195-200.

25. Mamlouk, M.; Ocon, P.; Scott, K., Preparation and characterization of polybenzimidzaole/diethylamine hydrogen sulphate for medium temperature proton exchange membrane fuel cells. Journal of Power Sources 2014, 245, 915-926.

26. Noble, R. D.; Gin, D. L., Perspective on ionic liquids and ionic liquid membranes. Journal of Membrane Science 2011, 369 (1-2), 1-4.

27. van de Ven, E.; Chairuna, A.; Merle, G.; Benito, S. P.; Borneman, Z.; Nijmeijer, K., Ionic liquid doped polybenzimidazole membranes for high temperature Proton Exchange Membrane fuel cell applications. Journal of Power Sources 2013, 222, 202-209.

28. Eguizábal, A.; Pina, M. P., Protic Ionic Liquids Confinement in Macro, Meso and Microporous Materials for Proton Conduction. In Encapsulation Nanotechnologies, John Wiley \& Sons, Inc.: 2013, pp 347-389.

29. Eguizábal, A.; J.Lemus; Roda, V.; Urbiztondo, M.; Barreras, F.; Pina, M. P., Nanostructured electrolyte membranes based on zeotypes, protic ionic liquids and porous PBI membranes: Preparation, characterization and MEA testing. International Journal of Hydrogen Energy 2012, 37 (8), 7221-7234.

30. Hopkinson, D.; Zeh, M.; Luebke, D., The bubble point of supported ionic liquid membranes using flat sheet supports. Journal of Membrane Science 2014, 468, 155-162.

31. Martinelli, A.; Nordstierna, L., An investigation of the sol-gel process in ionic liquidsilica gels by time resolved Raman and 1H NMR spectroscopy. Physical chemistry chemical physics : PCCP 2012, 14 (38), 13216-23. 
32. Li, M.; Yang, L.; Fang, S.; Dong, S., Novel polymeric ionic liquid membranes as solid polymer electrolytes with high ionic conductivity at moderate temperature. Journal of Membrane Science 2011, 366 (1-2), 245-250.

33. Mecerreyes, D., Polymeric ionic liquids: Broadening the properties and applications of polyelectrolytes. Progress in Polymer Science 2011, 36 (12), 1629-1648.

34. Yuan, J.; Antonietti, M., Poly(ionic liquid)s: Polymers expanding classical property profiles. Polymer 2011, 52 (7), 1469-1482.

35. Ye, Y.-S.; Rick, J.; Hwang, B.-J., Ionic liquid polymer electrolytes. J. Mater. Chem. A 2013, 1 (8), 2719-2743.

36. Yuan, J.; Mecerreyes, D.; Antonietti, M., Poly(ionic liquid)s: An update. Progress in Polymer Science 2013, 38 (7), 1009-1036.

37. Lemus, J.; Eguizábal, A.; Pina, M. P., UV polymerization of room temperature ionic liquids for high temperature PEMs: Study of ionic moieties and crosslinking effects. International Journal of Hydrogen Energy 2015, 40 (15), 5416-5424.

38. Shaplov, A. S.; Marcilla, R.; Mecerreyes, D., Recent Advances in Innovative Polymer Electrolytes based on Poly(ionic liquid)s. Electrochimica Acta 2015, 175, 18-34.

39. Lemus, J.; Eguizábal, A.; Pina, M. P., Endurance strategies for the preparation of high temperature polymer electrolyte membranes by UV polymerization of 1-H-3-vinylimidazolium bis(trifluoromethanesulfonyl)imide for fuel cell applications. International Journal of Hydrogen Energy 2016, 41 (6), 3981-3993.

40. Díaz, M.; Ortiz, A.; Vilas, M.; Tojo, E.; Ortiz, I., Performance of PEMFC with new polyvinyl-ionic liquids based membranes as electrolytes. International Journal of Hydrogen Energy 2014, 39 (8), 3970-3977.

41. Wojnarowska, Z.; Knapik, J.; Díaz, M.; Ortiz, A.; Ortiz, I.; Paluch, M., Conductivity Mechanism in Polymerized Imidazolium-Based Protic Ionic Liquid [HSO3-BVIm][OTf]: Dielectric Relaxation Studies. Macromolecules 2014, 47 (12), 4056-4065.

42. Le Bideat, J.; Viat, L.; Vioux, A., Ionogels, ionic liquid based hybrid materials. Chemical Society reviews 2011, 40 (2), 907-925.

43. Díaz, M.; Ortiz, A.; Isik, M.; Mecerreyes, D.; Ortiz, I., Highly conductive electrolytes based on poly([HSO3-BVIm][TfO] $) /[\mathrm{HSO} 3-\mathrm{BMIm}][\mathrm{TfO}]$ mixtures for fuel cell applications. International Journal of Hydrogen Energy 2015, 40 (34), 11294-11302.

44. Rewar, A. S.; Chaudhari, H. D.; Illathvalappil, R.; Sreekumar, K.; Kharul, U. K., New approach of blending polymeric ionic liquid with polybenzimidazole (PBI) for enhancing physical and electrochemical properties. Journal of Materials Chemistry A 2014, 2 (35), 1444914458.

45. Yamaguchi, T.; Zhou, H.; Nakazawa, S.; Hara, N., An Extremely Low Methanol Crossover and Highly Durable Aromatic Pore-Filling Electrolyte Membrane for Direct Methanol Fuel Cells. Advanced Materials 2007, 19 (4), 592-596.

46. Liang, B.; Jiang, Q.; Tang, S.; Li, S.; Chen, X., Porous polymer electrolytes with high ionic conductivity and good mechanical property for rechargeable batteries. Journal of Power Sources 2016, 307, 320-328.

47. Eguizábal, A.; Lemus, J.; Urbiztondo, M.; Garrido, O.; Soler, J.; Blazquez, J. A.; Pina, M. P., Novel hybrid membranes based on polybenzimidazole and ETS-10 titanosilicate type material for high temperature proton exchange membrane fuel cells: A comprehensive study on dense and porous systems. Journal of Power Sources 2011, 196 (21), 8994-9007. 
48. Jheng, L.-C.; Hsu, S. L.-C.; Tsai, T.-Y.; Chang, W. J.-Y., A novel asymmetric polybenzimidazole membrane for high temperature proton exchange membrane fuel cells. Journal of Materials Chemistry A 2014, 2 (12), 4225.

49. Eguizábal, A.; Sgroi, M.; Pullini, D.; Ferain, E.; Pina, M. P., Nanoporous PBI membranes by track etching for high temperature PEMs. Journal of Membrane Science 2014, 454, 243-252.

50. Gates, B. D.; Xu, Q.; Stewart, M.; Ryan, D; Willson, C. G.; Whitesides, G. M., New Approaches to Nanofabrication: Molding, Printing, and Other Techniques. Chemical Reviews 2005, 105 (4), 1171-1196.

51. Eguizábal, A.; Urbiztondo, M. A.; Pina, M. P., Pt based catalytic coatings on poly(benzimidazole) micromonoliths for indoor quality control. Catalysis Today 2015, 241, 114124.

52. Howlett, P. C.; Brack, N.; Hollenkamp, A. F.; Forsyth, M.; MacFarlane, D. R., Characterization of the Lithium Surface in N-Methyl-N-alkylpyrrolidinium Bis(trifluoromethanesulfonyl)amide Room-Temperature Ionic Liquid Electrolytes. Journal of The Electrochemical Society 2006, 153 (3), A595.

53. Hoarfrost, M. L.; Tyagi, M. S.; Segalman, R. A.; Reimer, J. A., Effect of Confinement on Proton Transport Mechanisms in Block Copolymer/Ionic Liquid Membranes. Macromolecules 2012, 45 (7), 3112-3120.

54. Bauer, F.; Denneler, S.; Willert-Porada, M., Influence of temperature and humidity on the mechanical properties of Nafion ${ }^{\circledR} 117$ polymer electrolyte membrane. Journal of Polymer Science Part B: Polymer Physics 2005, 43 (7), 786-795.

55. Trchová, M.; Šeděnková, I.; Morávková, Z.; Stejskal, J., Conducting polymer and ionic liquid: Improved thermal stability of the material - A spectroscopic study. Polymer Degradation and Stability 2014, 109, 27-32.

56. Singh, M. P.; Singh, R. K.; Chandra, S., Ionic liquids confined in porous matrices: Physicochemical properties and applications. Progress in Materials Science 2014, 64, 73-120. 